\title{
Cortical auditory deafferentation induces long-term plasticity in the inferior colliculus of adult rats: microarray and qPCR analysis
}

\author{
Cheryl Clarkson, M. Javier Herrero-Turrión and Miguel A. Merchán*
}

Instituto de Neurociencias de Castilla y León, Universidad de Salamanca, Salamanca, Spain

\section{Edited by:}

Eric D. Young, Johns Hopkins

University, USA

\section{Reviewed by:}

Avril Genene Holt, Wayne State University, USA

Richard Altschuler, University of Michigan, USA

*Correspondence:

Miguel A. Merchán, Laboratorio de Neurobiología de la Audición, Facultad de Medicina, Departamento de Biología Celular y Patología, Instituto de Neurociencias de Castilla y León, Universidad de Salamanca, C/Pintor Fernando Gallego, 1, Salamanca 37007, Spain.

e-mail:merchan@usal.es
The cortico-collicular pathway is a bilateral excitatory projection from the cortex to the inferior colliculus (IC). It is asymmetric and predominantly ipsilateral. Using microarrays and RT-qPCR we analyzed changes in gene expression in the IC after unilateral lesions of the auditory cortex, comparing the ICs ipsi- and contralateral to the lesioned side. At 15 days after surgery there were mainly changes in gene expression in the IC ipsilateral to the lesion. Regulation primarily involved inflammatory cascade genes, suggesting a direct effect of degeneration rather than a neuronal plastic reorganization. Ninety days after the cortical lesion the ipsilateral IC showed a significant up-regulation of genes involved in apoptosis and axonal regeneration combined with a down-regulation of genes involved in neurotransmission, synaptic growth, and gap junction assembly. In contrast, the contralateral IC at 90 days post-lesion showed an up-regulation in genes primarily related to neurotransmission, cell proliferation, and synaptic growth. There was also a down-regulation in autophagy and neuroprotection genes. These findings suggest that the reorganization in the $\mathrm{IC}$ after descending pathway deafferentation is a long-term process involving extensive changes in gene expression regulation. Regulated genes are involved in many different neuronal functions, and the number and gene rearrangement profile seems to depend on the density of loss of the auditory cortical inputs.

Keywords: brain injury, gene expression profiling, corticofugal projection, long-term post-lesion, adult lesion plasticity

\section{INTRODUCTION}

The inferior colliculus (IC) is an obligatory relay station for almost all ascending and descending auditory projections and it is a key nucleus for excitatory and inhibitory auditory input convergence (Malmierca and Merchán, 2004). The descending cortico-collicular projection acts as a filter for neuronal responses (Sun et al., 2007). It participates in a positive feedback loop which, in combination with lateral inhibition, sharpens, and adjusts the tuning of neurons in the auditory pathway (Zhang et al., 1997; Jen and Zhang, 1999). The descending auditory corticofugal projection is glutamatergic and therefore excitatory (Feliciano and Potashner, 1995). It is bilateral, but is denser on the ipsilateral side (Saldana et al., 1996; Bajo et al., 2007). Corticofugal deactivation results in unbalanced excitatory/inhibitory IC afferent projections, which induce alterations in the amplitude and latencies of IC neuronal responses (Nwabueze-Ogbo et al., 2002; Popelar et al., 2003), indicating that this projection affects directly the activity of IC neurons.

The developmental auditory system exhibits great ability for network reorganization induced by sensory deprivation (Kandler, 2004; Keuroghlian and Knudsen, 2007). In adults, this capability to induce plastic changes is reduced but still present. In the auditory pathway, plastic changes in the adult have been tested using acoustic stimulation (Norena and Eggermont, 2006), trainingbehavioral methods (Edeline and Weinberger, 1991a,b, 1992; Gao and Suga, 1998, 2000; Ma and Suga, 2005; Rutkowski and Weinberger, 2005), adaptation after sensory deafferentation (Holt et al., 2005, 2006; Illing et al., 2005; Illing and Reisch, 2006; Rubio, 2006), and auditory cortex lesion (Druga and Syka, 2001; Bowen et al., 2003; Rybalko et al., 2006; Clarkson et al., 2010a,b,c).

In the IC partial deafferentation of the ascending auditory pathway reduced sound-evoked inhibitory collicular responses (Semple and Kitzes, 1985; Bledsoe et al., 1995; McAlpine et al., 1997; Vale and Sanes, 2002). Whole cell patch recordings in brain slices showed that bilateral deafness induced a decrease in lateral lemniscus neurotransmitter release and synaptic strength variations in both excitatory and inhibitory IC synapses (Vale and Sanes, 2002). It is known that changes in the balance of excitation and inhibition trigger synaptic plasticity, adapting biophysical membrane properties (synaptic strength and axon conductance properties) or modifying the synthesis and trafficking of receptors (Perez-Otano and Ehlers, 2005; Turrigiano, 2012). Holt et al. (2005) suggested unbalanced excitation and inhibition as a basis for long-term (90 days) changes in adult IC gene expression after inactivation of the ascending auditory pathway by bilateral cochleotomy. Ascending lemniscal connections to the IC include both excitatory and inhibitory fibers (Riquelme et al., 2001). Therefore ascending deafferentation included a loss of both excitatory and inhibitory inputs. However, the descending pathway is solely excitatory, and its absence should lead to a strong 
unbalance of excitation and inhibition with consequences in gene expression, which are currently unknown.

We have previously used an auditory cortical ablation model in adult rats to analyze long-term plastic changes in the IC (Clarkson et al., 2010a,b,c). We demonstrated that restricted cortical ablation in acoustically stimulated animals strongly decreased c-Fos immunoreactivity in IC neurons at 15 days post-lesion, with a significant recovery taking place after 90 days (Clarkson et al., 2010a). It is well known that c-Fos immunoreactivity is an anatomical marker of neuronal activity (Bullitt, 1995), and that its alteration may be related to changes in neuronal transcription (Kovacs, 2008). Based on our c-Fos results (Clarkson et al., 2010a), we suggest that time-dependent activation of IC neurons after long-term cortical deprivation may be a consequence of the reorganization of auditory pathway projections. In the Central Nervous System, mechanisms of neural plasticity underlying long-term network reorganization such as collateral sprouting and pruning, cell death, neurotransmitter regulation, or glial functional differences, are reflected in changes in levels of gene expression (Wieloch and Nikolich, 2006). To gain insights into long-term plastic changes after descending IC deafferentation, we have used in our auditory cortex ablation animal model (Clarkson et al., 2010a,b,c) a Gene Chip Microarray technology, validated by quantitative reverse transcription real-time PCR (RT-qPCR).

\section{MATERIALS AND METHODS EXPERIMENTAL ANIMALS}

All experiments were performed according to national (R.D. 1201/2005) and EU regulations (DOCE L 222; 24-08-1999) for use and care of animals in research. Nine male rats (Wistar albino, Charles River Laboratories) weighing $230 \mathrm{~g}$ and 12 weeks of age at the beginning of experiments were used. Animals were free of ear infection and for a quick assessment of normal hearing we used in all cases bilateral finger friction test. For DNA microarrays analysis we used both IC (ipsilateral and contralateral) from three animals in each group (naïve control, 15 days post-lesion and 90 days postlesion). For RT-qPCR three replicates from control and 90 days post-lesion group (both ICs) were randomly selected and run in triplicate twice for each gene product (25 genes).

\section{SURGERY AND AUDITORY CORTEX LESION LOCALIZATION}

Animals were anesthetized with ketamine chlorhydrate $(30 \mathrm{mg} / \mathrm{Kg}$, Imalgene $^{\circledR}$ 1000, Rhone Méreuse, Lyon, France) and xylazine chlorhydrate (5 mg/Kg Rompun ${ }^{\circledR}$, Bayer, Leverkusen, Germany). Unilateral ablation by aspiration of the left auditory cortices (primary - Au1, dorsal - AuD, and ventral - AuV areas), including cortical layers V and VI, was carried out under stereotaxic control using a stereotaxic frame (David Kopf Ins., Tujinga, CA, USA) following a procedure described in detail elsewhere (Clarkson et al., 2010b).

Following the appropriate number of days post-lesion, ablated, and naïve control animals were deeply anesthetized with sodium pentobarbital $(60 \mathrm{mg} / \mathrm{kg})$ and decapitated. After quickly exposing the brain stem, both ICs were removed and the brain was stored overnight in a solution of $4 \%$ paraformaldehyde in phosphate buffer (PB) $0.1 \mathrm{M}, \mathrm{pH}$ 7.4. Finally, the brains were cryoprotected in $30 \%$ sucrose in $0.1 \% \mathrm{~PB}$ and serially sectioned at $40 \mu \mathrm{m}$ to quantify the percentage of auditory cortices affected by ablation (Clarkson et al., 2010a,b).

\section{RNA ISOLATION}

Collected ICs were homogenized and total RNA was purified using TRIZOL $^{\circledR}$ (Gibco BRL, Gaithersburg, MD, USA). RNA quality was assessed and quantitated by Agilent 2100 Bioanalyzer software (Agilent Technologies, Palo Alto, CA, USA) associated with a RNA 6000 Nano kit. A RNA integrity number (RIN) > 8.0 were found in all samples. In addition, further RNA purification using an RNeasy Mini Kit for RNA clean-up (Qiagen Sciences, Maryland, USA) was performed.

\section{MICROARRAY, DATA, AND ONTOLOGICAL ANALYSIS}

Microarray analyses were performed at the Cancer Research Center (Centro de Investigacion del Cancer - CIC) at the University of Salamanca (Spain). Labeling and hybridizations were performed according to Affymetrix protocols. One hundred to three hundred nanograms of total RNA were amplified and labeled using the WT Sense Target labeling and control reagents kit (Affymetrix Inc., Santa Clara, CA, USA), and hybridized to Rat Gene 1.0 ST Array (Affymetrix). Washes and scans were performed using GeneChip System of Affymetrix (GeneChip Hybridization Oven 640, GeneChip Fluidics Station 450, and GeneChip Scanner 7G).

Following image analysis, microarray data were imported into GeneSpring GX 7.3 (Agilent Technologies). RMA (Robust Multiarray Analysis), a method for normalizing and summarizing probe-level intensity measurements, was used. For this analysis, all genes that did not change between samples were excluded. We compared the experimental samples with naïve controls; all our samples passed a high data quality control, showing a high homogeneity intra-group (Datasheet 1 in Supplementary Material). Potential differential expression was determined with a one-way analysis of variance ANOVA (variances not assumed to be equal) and subsequently an unpaired $t$-test, $p<0.05$, filtered for 1.5 -fold was made in order to search differences in the gene expression (control samples were used as basal levels). Further processing including functional analysis and overrepresentation calculations based on Gene Ontology (GO) Annotation Tool and publication data from Database for Annotation, Visualization, and Integrated Discovery were made with GeneSpring GX 7.3 and Database for Annotation, Visualization, and Integrated Discovery (DAVID) Bioinformatics Resources 6.7 (http: //david.abcc.ncifcrf.gov/; Dennis et al., 2003; Huang et al., 2009).

Only genes with a Fold Change (FC) $>1.5$ (up or down), were considered for analysis (Datasheet 1 in Supplementary Material). From this group of genes we centered our attention in categories reported altered in the IC after auditory cortical lesion or are related directly to post-lesional plasticity (genes shown in Figures 2-4).

\section{QUANTITATIVE REVERSE TRANSCRIPTION REAL-TIME PCR}

Total RNA $(2 \mu \mathrm{g})$, primed with oligo-dT, was reverse-transcribed into $\mathrm{CDNA}$ at $37^{\circ} \mathrm{C}$ for $2 \mathrm{~h}$ using the first-strand cDNA synthesis kit (Promega Corporation, Madison, WI, USA). In all cases, a reverse transcriptase negative control was used for testing genomic DNA contamination. RT-qPCR was carried out on a real-time detection instrument (ABI Prism 7300 system) in 96-well optical plates 
using TaqMan Universal PCR Master Mix and Assay on Demand primers and probes. Probe sets used are listed in Datasheet 2 in Supplementary Material. Reaction components included: 2X TaqMan Universal Master Mix with UNG, $450 \mathrm{nM}$ unlabeled PCR primers, $125 \mathrm{nM}$ FAM dye-labeled TaqMan MGB probe, and $1 \mu \mathrm{L}$ cDNA reaction product in a $10 \mu \mathrm{L}$ total reaction volume. PCR conditions were as follows: $2 \mathrm{~min}$ at $50^{\circ} \mathrm{C}, 10 \mathrm{~min}$ at $95^{\circ} \mathrm{C}$ and 40 cycles of $15 \mathrm{~s}$ at $95^{\circ} \mathrm{C}$ and $1 \mathrm{~min}$ at $60^{\circ} \mathrm{C}$. Relative quantities were calculated using the $2^{-\Delta \Delta \mathrm{Ct}}$ analysis method (Schmittgen and Livak, 2008) with GAPDH (Glyceraldehyde-3-phosphate dehydrogenase: Rn99999916_s1) as the endogenous control. $2^{-\Delta \Delta \mathrm{Ct}}$ values were analyzed using One-way analysis of variance (ANOVA; $p<0.05)$ with a post hoc Student Newman-Keuls test $(p<0.05)$ was performed for statistical analysis.

\section{RESULTS}

We analyzed differences in gene expression profiling in the IC in the short (15 days) and long-term range (90 days) after unilateral auditory cortex ablation. In addition, as this is an anatomically asymmetric projection in terms of innervation density, we also studied the differences in gene expression between the ipsi- and contralateral IC at each time post-lesion. Comparisons between control and deafferented groups showed gene products corresponding to a total of 24,070 probes (of the 27,342 total probes on the arrays) which were confidently detected based on signal intensity at a fixed value above background level (See Material and Methods, Robust Multi-array Analysis, RMA).

To enhance biological interpretation of the differentially expressed genes we performed function enrichment analysis for these genes using the functional classification tool "DAVID Bioinformatics." Our results indicated that, although there were many over-represented biological function group of genes as shown in Datasheet 3 in Supplementary Material, the majority of them were related to a few functional categories. In our study the most relevant categories included genes related to neurotransmission and signal propagation such as receptors for glutamate, glycine, acetylcholine, or serotonin. This classification also involves enzymes and neurotransmitter transporters (glutamate, $\gamma$-aminobutyric acid (GABA), and glycine) and different types of channels (chloride, potassium, sodium, and calcium). Other functional categories notably detected include genes encoding proteins implicated in neural/synaptic plasticity, axonal growth/degeneration, myelin organization, and regulation, sprouting, neuroprotection, immune response, regulation of apoptosis, autophagy, and cell proliferation, migration, and differentiation.

All unilateral ablations were restricted in depth to the cortical gray matter (including layer 6) and their extension mainly affected the primary and secondary auditory cortices with an average of $69.74+4.7 \%$ for 15 days post-lesion group and $74.19+9.4 \%$ in the group 90 days post ablation (Figure 1).

\section{CONTROL VS. 15 DAYS POST-LESION IN THE IPSILATERAL IC AND CONTROL VS. 15 DAYS POST-LESION IN THE CONTRALATERAL IC}

Microarray comparisons between control and lesioned cases after 15 days showed that the genomic profile in the IC ipsilateral to the side of the lesion was slightly affected with 19 genes significantly up-regulated $(\mathrm{FC}>1.5$ and $p<0.05)$ and 14 genes significantly down-regulated (Figure 2A and Datasheet 1 in Supplementary Material). The IC contralateral to the side of the lesion also followed a similar trend with 16 genes up-regulated and three downregulated (Figure 2B and Datasheet 1 in Supplementary Material).

After examining the potential function for each significantly affected gene per lesioned side we found that after 15 days postlesion, the ipsilateral IC which had lost a denser cortical projection had a major up-regulation in several genes involved in inflammatory pathways (Serglycin, Srgn; Podocalyxin, Podx; Complement Component 3, C3; and Claudin 5, Cldn5) and stem cell regeneration (Prominin 1, Prom1). On the other hand, one gene directly related with neuroprotection (Latexin, $L x n$ ) was clearly downregulated (Figure 2C). Furthermore, the contralateral IC that had lost a weaker projection showed an up-regulation in genes involved in inflammation processes ( $N A D H$ dehydrogenase subunit 6 I Cytochrome c oxidase subunit 3, Nd6lCox3) and synaptic growth (Spinster, Spns; Figure 2D).

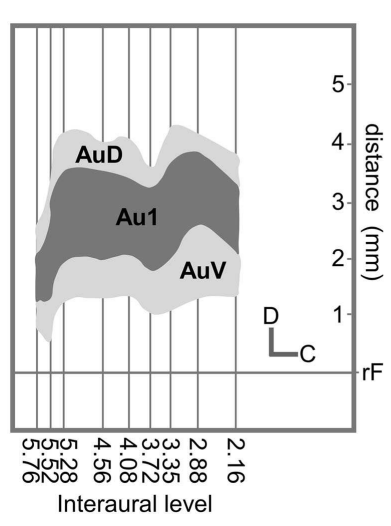

FIGURE 1 | Location and percentage of auditory cortical lesion for all cases used after $\mathbf{1 5}$ and $\mathbf{9 0}$ days post-lesion. On the left, the diagram shows the representation in our cases of primary and secondary auditory cortices (Clarkson et al., 2010a) for all interaural levels drawn by Paxinos and
Watson (2005). We used like reference for the coordinates of the vertical axis the distance in $\mathrm{mm}$ from rhinal fissure. Right side, superimposition of each lesion contours over auditory cortex diagram. AuC, Primary auditory cortex; AuV, Ventral auditory cortex; AuD, Dorsal auditory cortex. 


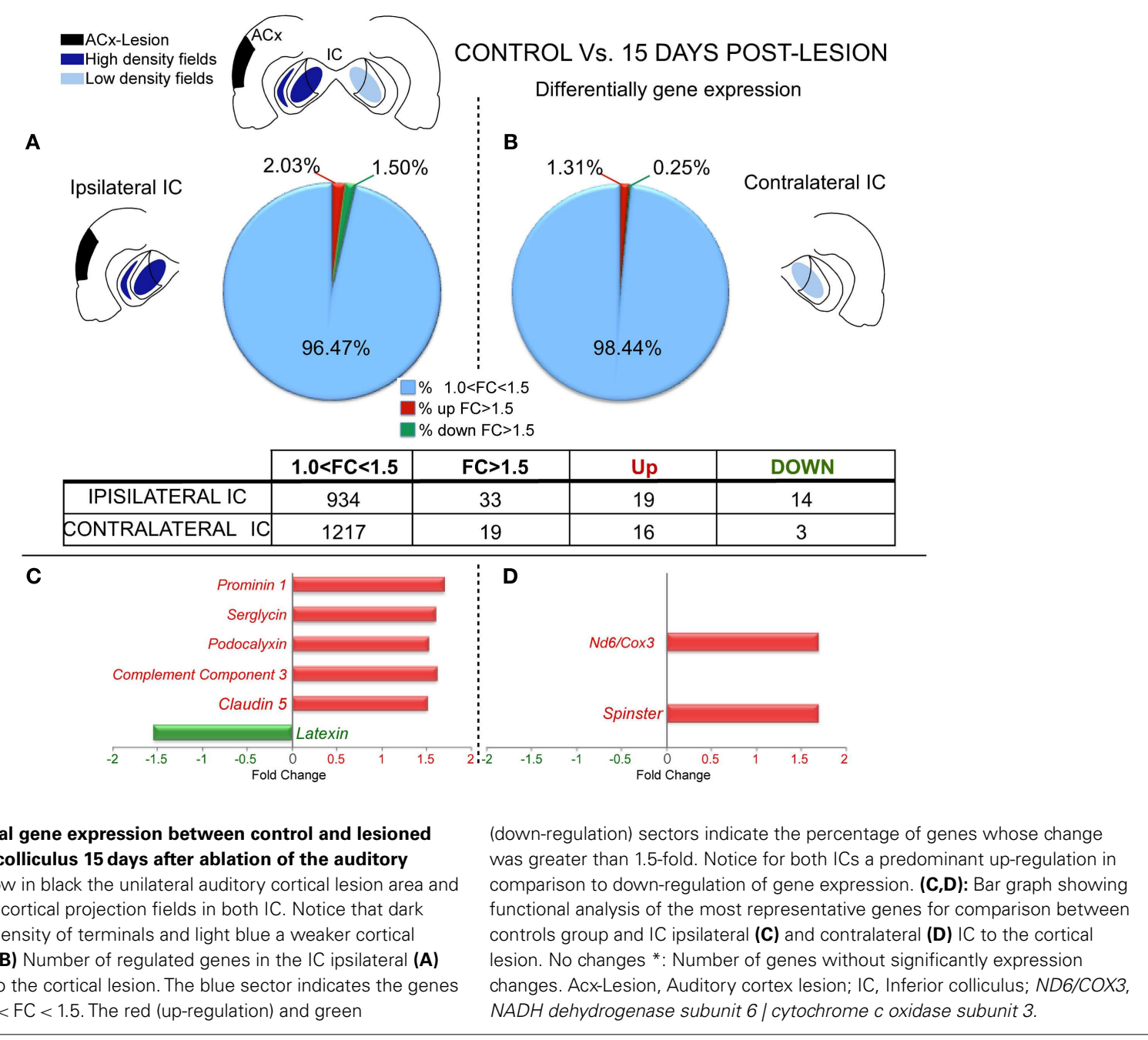

\section{CONTROL VS. 90 DAYS POST-LESION IN THE IPSILATERAL IC AND CONTROL VS. 90 DAYS POST-LESION IN THE CONTRALATERAL IC}

The analysis of gene expression after 90 days post-lesion, on both the ipsi- and contralateral sides, showed greater changes compared to control than did the 15 -days group. The ipsilateral side (90 days) displayed up-regulation of 322 genes and down-regulation in 108 genes (Figure 3A and Datasheet 1 in Supplementary Material). In the contralateral IC, 146 genes were up-regulated and 64 genes were down-regulated (Figure 3B and Datasheet 1 in Supplementary Material).

In particular, after 90 days post-lesion, gene function analysis showed that the ipsilateral IC had significant adjustments in genes involved in neurotransmission and signal propagation. Specifically, five were clearly down-regulated: Calcium channel voltage-dependent - $\gamma 3$, Cacng3; Potassium inwardly rectifying channel, subfamily J, member 16, Kcnj16; Adducin 1 (alpha), Add1; Claudin 11, Cldn11; and Calsyntenin 3, Clstn3, and one was up-regulated (Sodium channel and clathrin linker 1, Sclt1; Figure 3C). We also found up-regulation in the expression of genes potentially involved in apoptotic processes (Programmed cell death 10, Pdcd10; Growth arrest-specific 2, Gas2; Fission 1,
Fis1; and Cytochrome c oxidase subunit VIIb, Cox7b) and downregulation in an anti-apoptotic gene (Gelsolin, Gsn). At the same time, the NADH dehydrogenase, subunit 6 Icytochrome $c$ oxidase III ( Nd6lCox3) gene involved in inflammatory response also showed up-regulation at this time post-lesion. Additionally, genes involved in synaptic growth, such as Myelin-associated glycoprotein (Mag) and Cadherin 13 (Cdh13), also displayed down-regulated expression, accompanied by up-regulation in one gene related to axonal degeneration (Calpain 7, Capn7). Furthermore, Gap junction proteins $\alpha 1$ and $\beta 6$ (Gja1 and Gjb6), also named Connexin 43 and 30, respectively, showed downregulation in gene expression. Finally, relevant genes for calcium regulation like (Nucleobindin 1,Nucb1) and calcium sensors like Synaptotagmin XI (Syt11) were down-regulated (Figure 3C).

Ninety days after the cortical lesion, the contralateral IC exhibited larger changes in the expression of genes related with neurotransmission than at 15 days, showing an up-regulation in Dopamine receptor D1 interacting protein gene (Drd1ip, also named Calcyon); Synaptogyrin 3 (Syngr3); Synaptic vesicle related protein (SV2); Opioid receptor-like 1 (Oprl1); Potassium voltage 


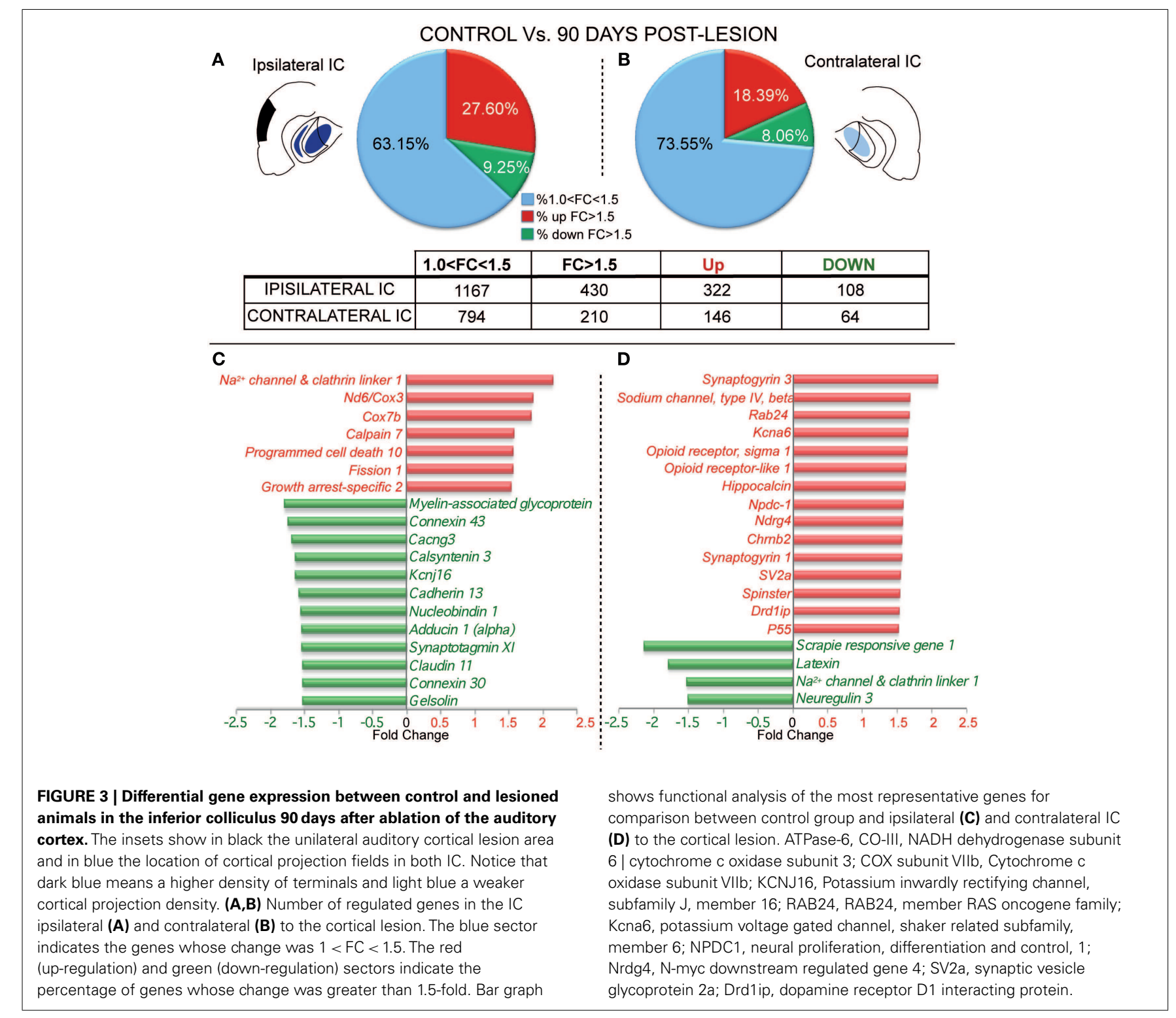

gated channel, shaker related subfamily, member 6 (Kcna6), and Sodium channel, type IV, beta gene (Scn4b; Figure 3D). Furthermore, Neuregulin 3 (Nrg3) and Sodium channel and clathrin linker 1 (Sclt1) genes involved in neurotransmission were downregulated. Interestingly, we found up-regulation in genes related to neural plasticity like Opioid receptor, sigma 1 (Oprs1); Hippocalcin (Hpca); P55; Synaptogyrin family (Syngr1 and 3), and also in genes that regulate synaptic growth, like Spinster, and cell proliferation, such as $N$-myc downstream regulated gene 4, (Ndrg4), and Neural proliferation, differentiation and control, 1 (Npdc1; Figure 3D). In contrast, we found at this time/side down-regulation in Latexin, which is involved in neuroprotection. Mixes of genes related with autophagy were also affected, with an up-regulation in RAB24, member RAS oncogene family and a down-regulation in Scrapie responsive gene 1 (Scrg1; Figure 3D).
IPSI- VS. CONTRALATERAL CHANGES AT 15 AND 90 DAYS POST-LESION

Unbalanced cortical inputs to the IC induced by unilateral cortical ablation seem to induce complex gene regulation patterns which are better appreciated by comparing the IC ipsi - and contralateral to the ablation side. In naïve control group, we did a comparison between ipsilateral and contralateral IC profiling and no significant FC in gene expression were found. Moreover, both ICs ipsi- and contralateral to the cortical lesion showed quantitatively slight alterations in gene expression after short-term post-lesion (15 days), with changes in 14 genes (Datasheet 2 in Supplementary Material). Of these genes, two have a known function as mediators of inflammatory processes and exhibit a down-regulation in the contralateral IC.

At long-term post-lesion (90 days), a much larger adjustment in gene expression was found, with 1659 probes significantly altered, i.e., 802 genes up-regulated and 857 genes down-regulated 
(Figure 4A and Datasheet 1 in Supplementary Material). Analysis of genes function showed changes in 54 genes related with neurotransmission. These changes covered a wide range of neurotransmission processes, with up-regulation of glutamate receptor genes (Glutamate receptor, ionotropic, N-methyl D-aspartate; Grin1, or Nmdar1), glycine receptor (Glycine receptor alpha 1, Glra1), acetylcholine receptor subunits (Cholinergic receptor, nicotinic, beta polypeptide 2; Chrnb2), a serotonin receptor subunit (5hydroxytryptaine-serotonin receptor $1 A, H \operatorname{tr} 1 a)$ and other receptorlike Oprs1. We also found up-regulation in five neurotransmitter synthesis enzyme genes [for glutamate: Glutaminyl-tRNA synthetase (Qars); for GABA: Glutamic acid decarboxylase 1 (Gad1) and 4-aminobutyrate aminotransferase (Abat); for glycine: GlycyltRNA synthetase (Gars); and for endocannabinoid mobilization through metabotropic glutamate receptors (mGluRs): Dyacylglycerol lipase alpha (Dagla)]. The neurotransmitter transporters also were affected. Two glutamate transporters genes were up-regulated Solute carrier family 17 (sodium-dependent inorganic phosphate cotransporter) member 6, Slc17a6, or also named Vesicular glutamate transporter 2 (VGlut2); and Solute carrier family 1 (Glial high affinity glutamate transporter) member 3, Slc1a3 or GLAST. Two GABA transporters (Solute carrier family 6-member 11 and family

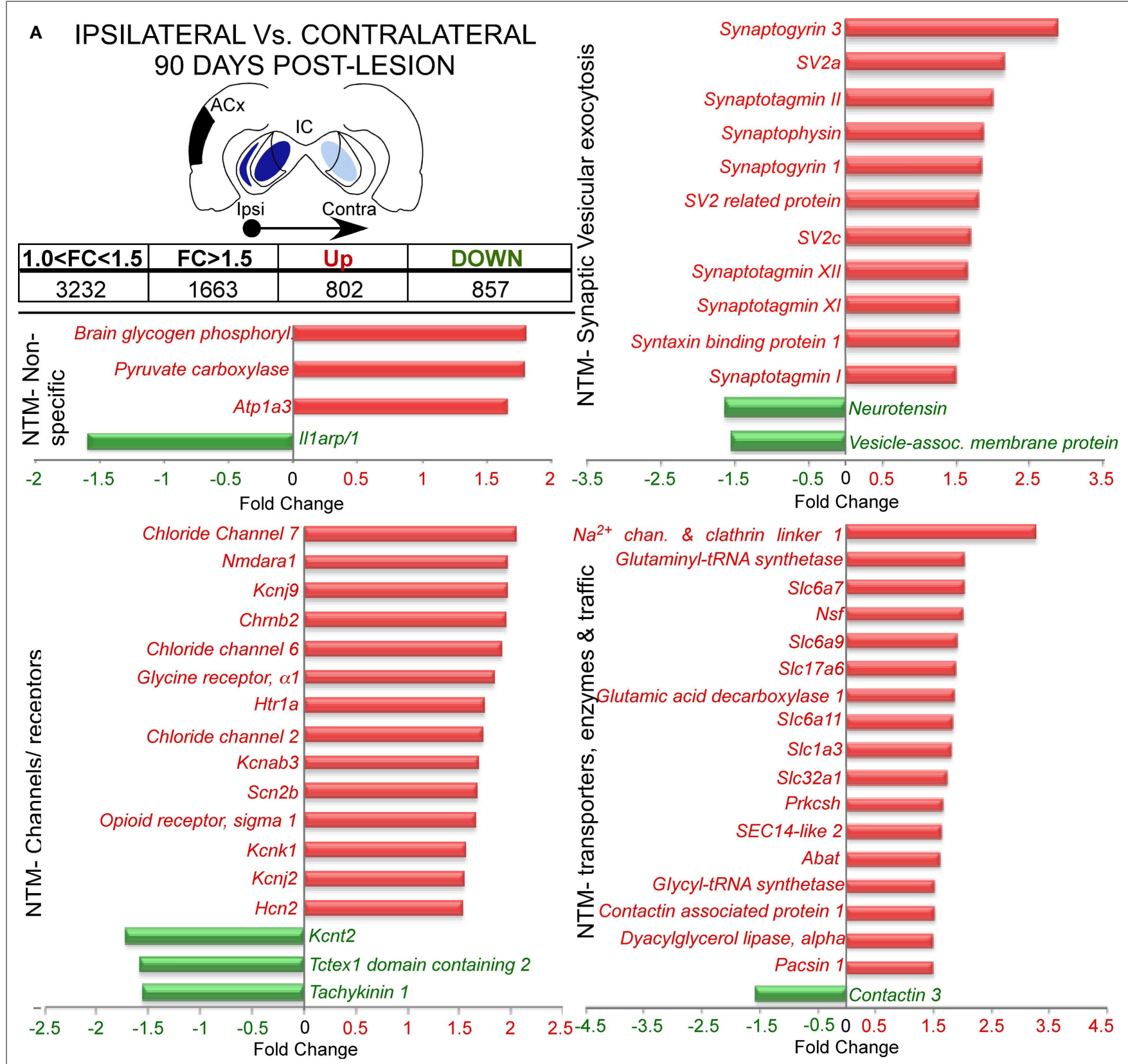

FIGURE 4 | Continued 


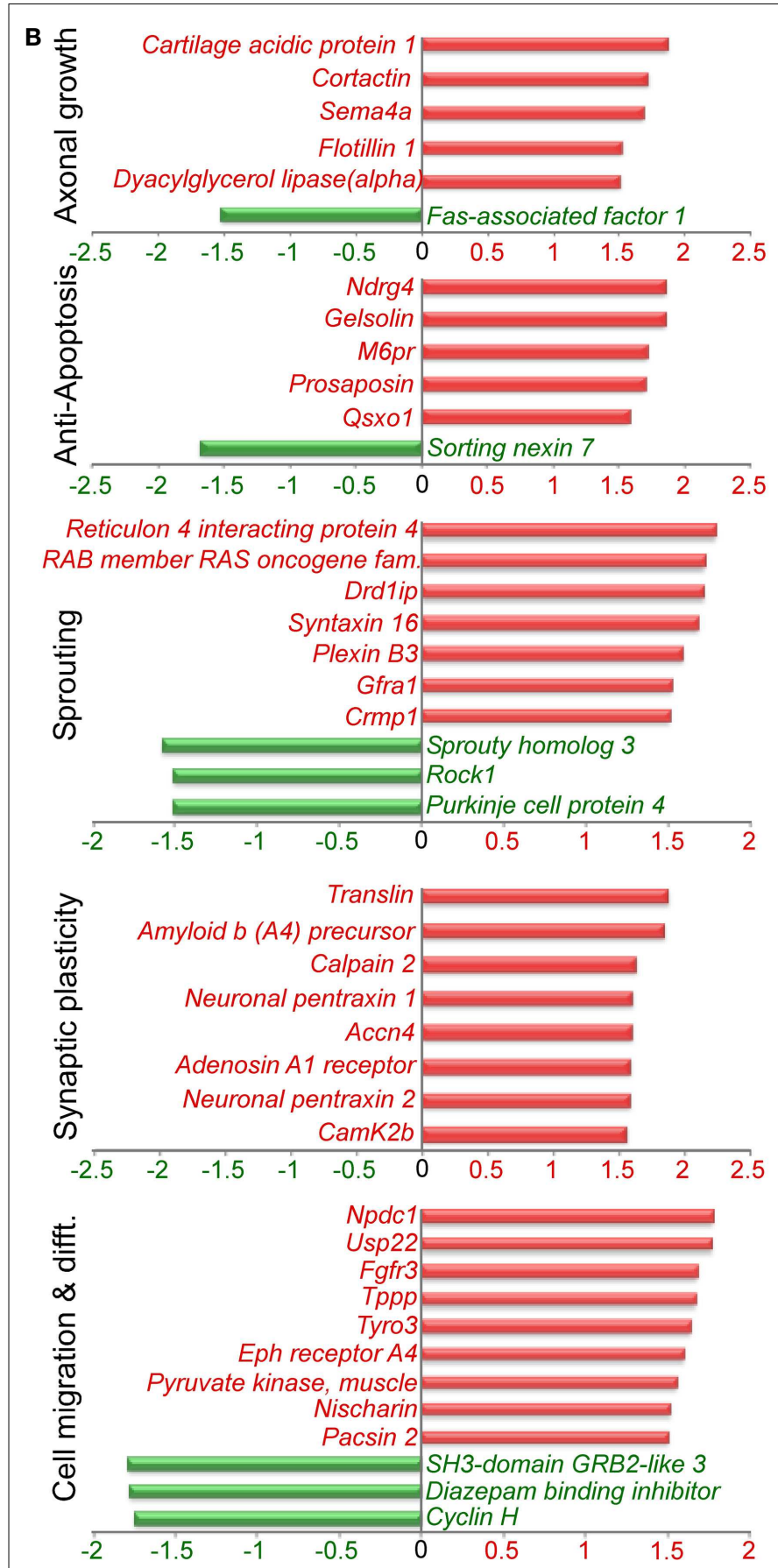

FIGURE 4 | Several of the most representative differentially expressed genes in the comparison between 90 days post-lesion in the ipsilateral IC vs. $\mathbf{9 0}$ days post-lesion in the contralateral IC. The inset shows in black the unilateral auditory cortical lesion area and in blues the location of cortical projection fields in both inferior colliculus. Notice that dark blue means a
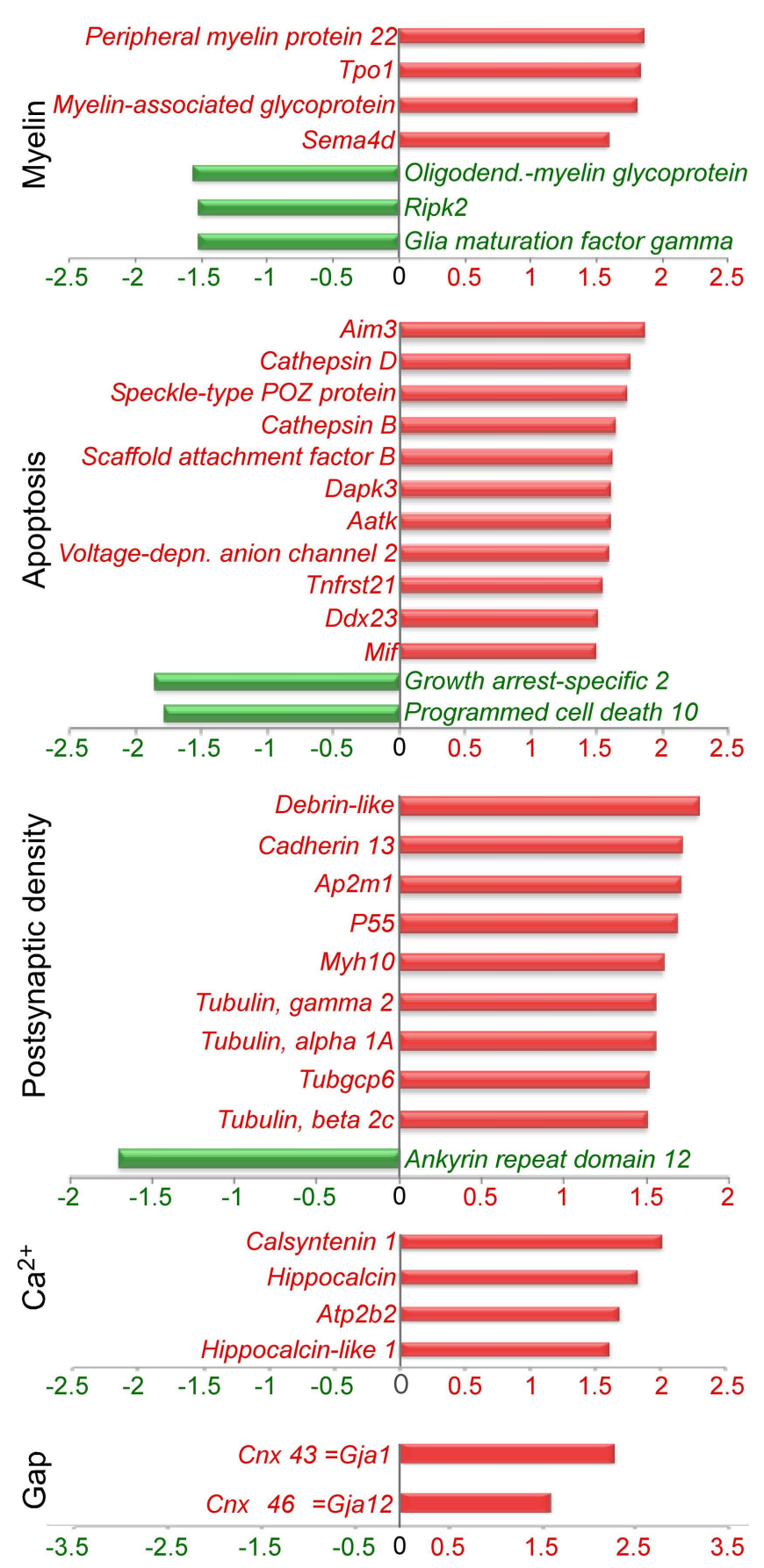

higher density of terminals and light blue a weaker cortical projection density. Graph bar showing functional analysis of the most representative genes in each functional category. (A) Neurotransmission (NTS). (B) Axonal growth, anti-apoptosis, sprouting, synaptic plasticity, cell migration and differentiation, myelin, apoptosis, postsynaptic density, $\mathrm{Ca}^{2+}$ and Gap junctions.
32 - member 1, Slc6a11, and Slc32a1, respectively), one glycine transporter [Solute carrier family 6 member 9, Slc6a9] and one proline transporter [Solute carrier family 6 member 7, Slc6a7] were also up-regulated. Up-regulation affected genes related with receptor trafficking as well, such as those for $\alpha$-amino-3-hydroxy-5-methyl4-isoxazolepropionic acid (AMPA) receptors: $N$-ethylmaleimide sensitive fusion protein (Nsf) and Contactin associated protein 1 (Cntnap1). Also for acetylcholine receptors: SEC14-like 2 and for 
sodium channel internalization with Sodium channel and clathrin linker 1 (SLCT1). Moreover, the Contactin 1 (Cntn1) gene that regulates traffic and synaptic content of AMPA receptors showed down-regulation after 90 days post-lesion (Figure 4A).

In addition, voltage-operated and other non-ligand gated ion channel genes were also up-regulated. These included three chloride channel genes (Clcn2, 6, and 7), five potassium channels $\left[\mathrm{K}^{+}\right.$inwardly rectifying channel subfamily $\mathrm{J}-$ members 2 and 9 (Kcnj2 and 9); $K^{+}$voltage gated channel shaker related subfamily $\beta 3$ (Kcnab3); $K^{+}$channel subfamily $K$ - member 1 (Kcnk1); and Hyperpolarization activated cyclic nucleotide-gated $K^{+}$channel 2 (Hcn2)] and a sodium channel [sodium channel voltage-gate, type II $(\operatorname{Scn} 2 b)]$. Additionally, a channel for potassium $\left[\mathrm{K}^{+}\right.$channel subfamily $T$ - member 2 (Kcnt2)], another for calcium regulation (Tctex1 domain containing 2, Tctex1d2) and one receptor for substance P (Tachykinin 1, Tac1) were down-regulated (Figure 4A). It is important that the synaptic vesicular machinery was also affected, with an up-regulation of genes involved in neurotransmitter release, as well as calcium sensors for exocytosis, such as Syngr1 and 3, the Synaptotagmin family (Syt1, 2, 11, and 12) and $S V$ family ( $S V 2 a$ and $c$ ), and genes related with synaptic vesicle plasticity such as Synaptophysin and genes associated with synaptic vesicle docking and fusion (Syntaxin binding protein 1, Stxbp1, and Syntaxin 16, Stx16; Figure 4A).

Furthermore, as shown in Figure 4B, we found up- or downregulation in genes involved in axonal growth and guidance, such as cortactin (Cttn) and Dyacylglycerol lipase, alpha (Dagla). At the same time, we detected changes in genes involved in myelin organization and regulation as Peripheral myelin protein 22 (Pmp22) and Developmentally regulated protein TPO1 (Tpo1), Myelin-associated glycoprotein (Mag), and Oligodendrocyte-myelin glycoprotein $(\mathrm{Omg})$. We also found both types of regulation in genes involved in sprouting [dopamine receptor D1 interacting protein (Drd1 ip), Sprouty homolog 3 (Spry-3), and Rho-associated coiled-coil containing protein kinase 1 (Rock1)], in synaptic plasticity [Amyloid beta (A4) precursor protein (App), Neuronal pentraxin 2 (Nptx2) and Calcium/calmodulin-dependent protein kinase II, $\beta$ Camk2b] and in postsynaptic density reorganization ( $p 55$, and Tubulins $\gamma 2, \alpha 1 A$, and $\beta 2 C$ ). In addition, even after 90 days postlesion, we still found regulations (up or down) in apoptotic genes, such as Cathepsins B and D (Ctsb and Ctsd), Growth arrest-specific 2 (Gas2) and Programmed cell death 10 (Pdcd10), but at the same time we found an increase in anti-apoptotic gene expression $[N$ myc downstream regulated gene 4 (Ndrg4) and Gelsolin (Gsn)]. This regulation was accompanied by changes in genes involved in cell migration and differentiation [e.g., Neural proliferation, differentiation and control, 1 (Npdc1) and Diazepam binding inhibitor $(D b i)$ and glial connexins [Gap junction membrane channel protein alpha 12 (Gja12), and gap junction protein, alpha 1 (Gja1 or Cnx43)].

\section{RT-qPCR ANALYSIS}

RT-qPCR analysis was used to confirm a subset of gene expression changes observed in the microarray analysis. Genes chosen for RT-qPCR confirmation were mainly selected 90 days after cortical ablation, based on ontological categories with potential functional roles.
Differentially regulated genes confirmed by RT-qPCR belong to a majority of functional categories already described (neurotransmission, neural/synaptic plasticity, axonal growth/degeneration, myelin organization and regulation, sprouting, neuroprotection, regulation of apoptosis, and autophagy). Thus, as shown in Table 1, altered gene expression of the majority of genes, but not all, were confirmed by RT-qPCR.

Microarray analysis identified many neurotransmission-related genes with significant increases in expression at 90 days after unilateral auditory cortex ablation (Figure 4A). From these genes, 12 were further assessed with RT-qPCR and showed comparable changes. A serotonin receptor ( Htrla), a glutamate receptor (Grin1 or NMDAR1), an enzyme for GABA synthesis (Glutamic acid decarboxylase 1, Gad1), a gene involved in the regulation of AMPA receptors ( $N$-ethylmaleimide sensitive fusion protein, $N$ sf), a glutamate transporter Slc17a6 (=VGlut2), and two GABA transporters (Slc32a1 and Slc6a11) showed significant increases of 4.09-, 1.81-, 2.13-, 1.48-, 1.79-, 1.52-, and 1.87-fold at 90 days in the contra(vs. ipsilateral) IC, respectively. Increased gene expression at the same time point was seen for a cholinergic receptor (Chrnb2), NMDA receptor associated protein (Grina), Neuronal pentraxin 2 (Nptx2), and the glutamate transporter Slc1a3 (=GLAST) using microarrays analysis, whereas RT-qPCR did not confirm such a significant increase. Conversely, Nsf and VGlut2 had increased levels of expression at 90 days in the ipsilateral IC and genes like Grin1 and Gad1 also had increased levels of expression at the same time point in the contralateral IC by RT-qPCR analysis, whereas the microarray data did not show a significant change. Also, RT-qPCR for Nptx2 and a GABA transporter (Slc32a1) showed a 1.74- and 1.57 -fold decrease in expression at 90 days in the ipsilateral IC after unilateral auditory cortex ablation, whereas microarrays did not show significant changes. In contrast, increased gene expression was seen at 90 days in the contralateral IC for the Sodium chan$n e l$, type IV, beta (Scn4b) using microarrays analysis, whereas the RT-qPCR did not show a significant increase.

Microarray results for the neurogenesis-related genes or neuronal differentiation, such as Amyloid beta (A4) precursor protein $(A p p)$, Neural proliferation, differentiation and control, 1 (Npdc1), and $N$-myc downstream regulated gene 4 (Ndrg4), showed an increase in expression at 90 days in the contralateral IC vs. control and vs. ipsilateral IC, respectively, after unilateral auditory cortex ablation. On the other hand, decreased gene expression at 90 days in the contra vs. ipsilateral IC was seen in the Diazepam binding inhibitor (Dbi) using microarrays analysis, while the RT-qPCR did not show a significant increase. In contrast, this same gene showed 1.54-fold increase in expression at 90 days in the contralateral IC by RT-qPCR, whereas the microarray data did not show a significant change at this time point.

Other genes such as the enzyme involved in endocannabinoid mobilization Dyacylglycerol lipase alpha (Dagla), glial connexin Gjal (=Cnx43), Apoptosis-inducing factor mitochondrionassociated 3 (Aifm3), p55, and Gelsolin (Gsn) assessed by RT-qPCR showed expression levels which were also increased at 90 days in the contra vs. ipsilateral IC, whereas Myelin-associated glycoprotein (Mag), Rho-associated coiled-coil containing protein kinase 1 (Rock1), Syt1, and Scrapie responsive gene 1 (Scrg1) did not show significant changes. Moreover, the gene encoding the gap junction 


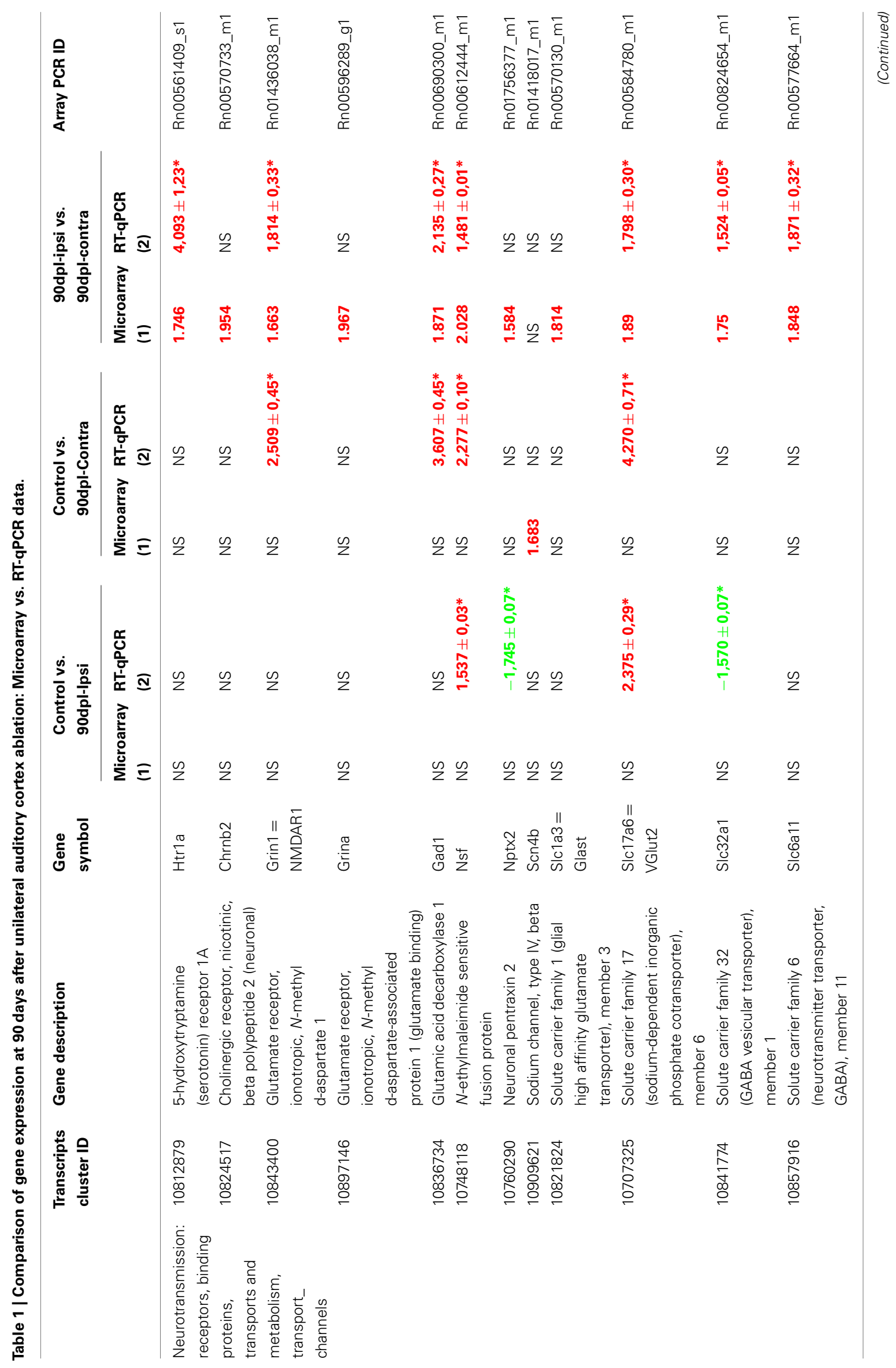




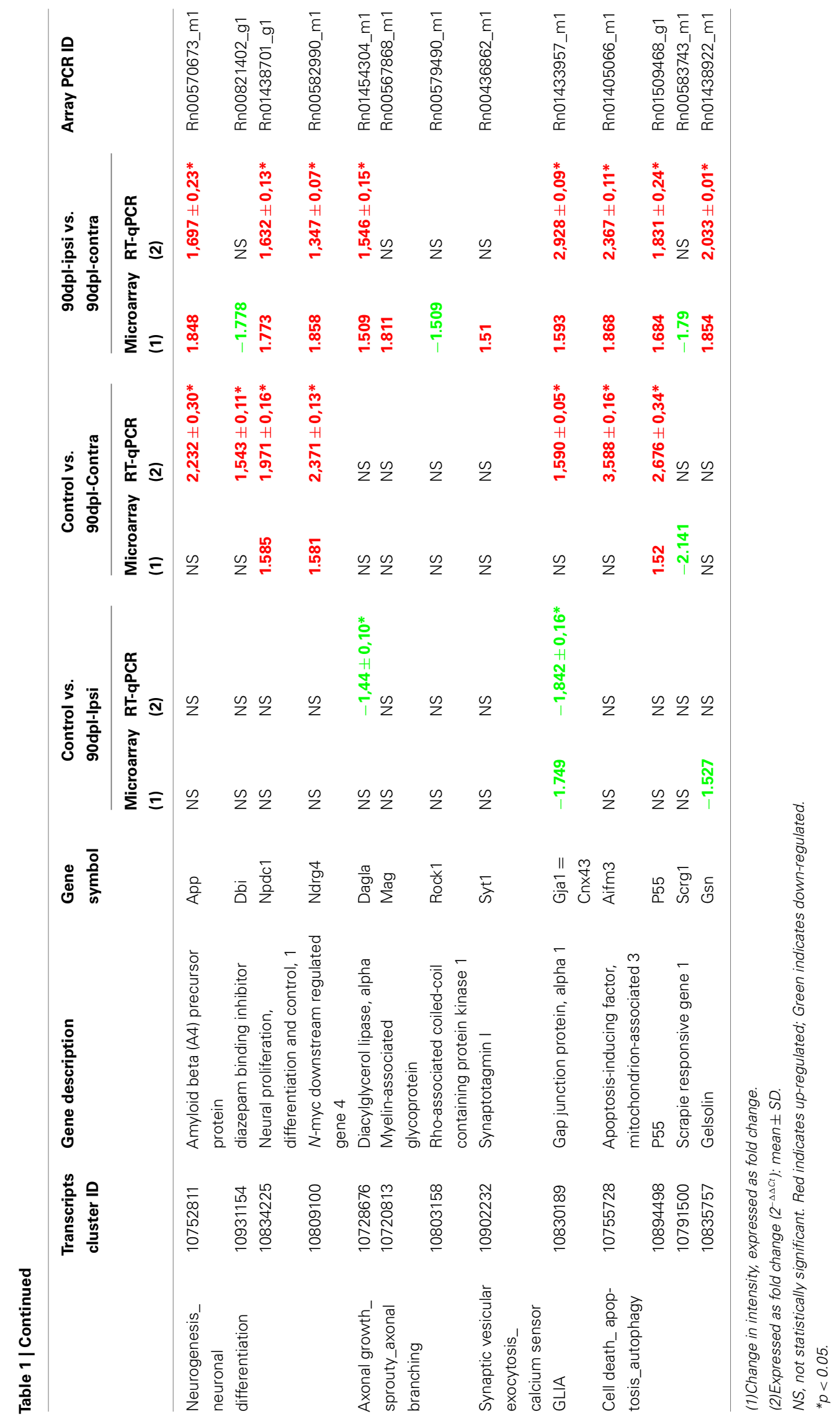


protein $C n x 43$ and p55 showed 1.84-fold decrease and 2.68-fold increase in expression at 90 days post-lesion in the ipsilateral and contralateral IC (vs. control), respectively, after unilateral auditory cortex ablation. A number of the RT-qPCR confirmation analysis (Dagla at 90 days in the ipsilateral IC, and Cnx43 and Aifm3 at 90 days in the contralateral IC) which did not reach statistical significance, demonstrated expression profiles similar to those observed in the microarray. On the other hand, Gsn at 90 days in the ipsilateral IC and Scrg1 at 90 days in the contralateral IC, showed changes in gene expression levels in microarrays, whereas the RT-qPCR did not show a significant increase.

As shown in Table 1, we performed RT-qPCR analysis on 24 genes at 90 days in the contra vs. ipsilateral IC after unilateral auditory cortex ablation and 15 of them showed similar changes in expression levels using microarrays analysis. Therefore, we used RMA for normalization that reflects more accurately the expression level of genes and a statistical method sufficiently stringent in assigning significance. We have observed differences in expression of some genes (e.g., Nptx2, Slc1a3, and $S c n 4 b$ ) using microarray analysis whereas RT-qPCR did not confirm such a significant variation. This situation was also described after microarray analysis in the IC by Holt et al. (2005), mainly in genes that are constitutively expressed at low levels. It should not be surprising that when constitute expression of genes is extremely low the threshold of microarrays are higher than qPCR arrays.

\section{DISCUSSION}

Unilateral auditory cortical deafferentation induces bilateral and asymmetric changes in gene expression profiling in the IC. In adults, this plastic response is time-dependent, with more extensive regulation at long-term post-lesion (90 days) than at shortterm (15 days). Also, the nature of this reorganization is different for each time post-lesion, supporting the concept of a plastic ability in adults.

Auditory cortical ablation affects a large number of genes simultaneously; at 15 days post-lesion we found 52 genes (33 in the ipsilateral side and 19 in the contralateral side) whose expression changes. Meanwhile, 90 days after the lesion this regulation affects 640 genes in the IC (430 in the ipsilateral side and 210 in the contralateral side). Unilateral cortical ablation strongly affects the ipsilateral lesioned side at both times post-lesion (15 and 90 days), due to the loss of a denser innervation. Ipsilateral regulation was greater after long-term (90 days) than after short-term. This "late" regulation suggests an important role for adult neural plasticity events in this key auditory nucleus. After 15 days post-lesion, gene expression regulation was mostly related to an inflammatory response, whereas after 90 days regulation was linked mainly to sprouting phenomena and synaptic transmission. We already know that the auditory system in adults is able to induce gene modulation in the IC even after long periods of peripheral deafferentation (Holt et al., 2005). Our approach has focused on a comparatively minor contralateral IC deafferentation and a stronger ipsilateral IC deafferentation resulting from unilateral cortical ablation. Our results show that this misbalance is enough to induce a rearrangement in gene expression profiles in the IC, involving the pathways necessary to trigger neuronal plasticity in adults. Neurons convert environmental stimuli using a complex array of signaling pathways and transcriptional mechanisms to orchestrate long-lasting changes in their physiology through the synaptic activity-regulated transcription of new gene products (Lyons and West, 2011). After auditory cortical lesions, these long-term transcriptional profiling changes in the bilateral ICs are an indication of adult synaptic plasticity triggers, which are dependent on both post-lesioned time and density deafferentation.

Our results are a first look at the entire post-lesional auditory plasticity process. To assess an IC reorganization after cortical ablation both genomic and proteomic analysis are necessary. Genomic results cannot be extrapolated to protein production since it is known that there exist some mismatches between genomic and proteomic data in both brain cell culture (Howley et al., 2012) and most specifically in auditory system nuclei (Bush and Hyson, 2008; Wang et al., 2009a,b). Wang et al. (2009b) found 80 days after sound exposure that GlyR $\alpha$ subunit message was increased in the dorsal cochlear nucleus. However, the protein level was decreased. Mechanisms for this mismatch are still unknown, but studies demonstrate that information regarding post-translational modifications of the proteins and their translocation is not inherently encoded in the gene sequences and cannot be derived from mRNA expression (see Benoit et al., 2011 review).

\section{THE IPSI- AND CONTRALATERAL IC 15 DAYS AFTER THE LESION TO THE CORTEX}

Functional analysis of IC gene profile expression 15 days after the lesion shows an up-regulation in Serglycin, a proteoglycan expressed primarily by immune cells (Kolset and Pejler, 2011) with a key role in inflammatory processes (Kolset and Tveit, 2008), suggesting that, in our model, cortical ablation induces in the short-term an inflammatory reaction in the ipsilateral IC which undergoes a larger loss of cortical descending afferents. In agreement with this finding, previous studies in the IC using a thiamine deficiency model to analyze inflammation, cellular stress, metabolism, and structural damage after focal neuronal death (Vemuganti et al., 2006) found an up-regulation in Podocalyxin, a cell adhesion regulator gene. More recently, other roles for this gene in neural development, neurite growth, branching, axonal fasciculation, and synapse formation after neuronal death or inflammation have been shown (Vitureira et al., 2010). In our experimental model, up-regulation of this gene in the ipsilateral IC suggests that this adjustment correlates with the density of the lesioned pathway. Furthermore, Complement component 3 (C3), another inflammation-related gene, was found to be up-regulated in the IC in thiamin deficiency animals (Vemuganti et al., 2006) and in our ablated animals; supporting the idea of an ongoing inflammatory process at 15 days post-lesion which is stronger in the ipsilateral IC, accordingly with a heaviest preterminal fields degeneration after cortical ablation in the ipsilateral IC rather than the contralateral (Feliciano and Potashner, 1995). In addition, Stevens et al. (2007) have demonstrated that $C 3$ is a gene that tagged synapses to be eliminated during CNS development. These authors suggest that complement-mediated synapse elimination (synaptic stripping) may become aberrantly reactivated in neurological diseases. The process of synaptic elimination (pruning), even in adult animals, is important for rewiring neural circuits. Butz et al. (2009), using a model for analyzing cortical rewiring after deafferentation 
showed that even small changes in homeostatic equilibrium imply formation of new synapses or pruning of existing ones.

On the other hand, in the ipsilateral IC at 15 days post-lesion we also found down-regulated genes, like Latexin which is a carboxypeptidase inhibitor which mediates inflammatory responses (Aagaard et al., 2005), but it also known to be expressed by astrocytes, providing neuroprotective mechanisms (Yata et al., 2011). However, our results suggest that a typical astrocytic reaction does not take place in the IC, because we did not find any regulation in marker genes for reactive astrocytes like Vimentin or Glial fibrillary acidic protein (GFAP) which in the case of a thiamine deficiency model were up-regulated (Vemuganti et al., 2006).

Analyses of the contralateral IC 15 days after the cortical lesion show an up-regulation in the Spinster (Spns) gene, which is a negative synaptic growth regulator. The Drosophila Spns mutant shows a $200 \%$ increase in the number of synaptic endings and a deficit in presynaptic release (Sweeney and Davis, 2002). Spinster is also linked to a novel caspase-independent cell death pathway mediated by autophagy (Yanagisawa et al., 2003). These data speak in favor of a rearrangement process in the contralateral IC that has lost a weaker corticofugal projection compared with the side ipsilateral to the lesion. The focus of this regulation may be in synaptic pruning, looking for an efficient synaptic rewiring (Butz et al., 2009), or it may be related to changes in presynaptic release after lesion (Birthelmer et al., 2003), which affects activity in IC neurons (Nwabueze-Ogbo et al., 2002; Popelar et al., 2003).

In summary, microarray analyses at 15 days post-lesion show that genes mainly related to inflammatory processes were upregulated in the ipsilateral IC. The relative increase in the activity of genes related to inflammation could be a consequence of extensive brain injury (Block et al., 2005). However the asymmetry of the corticofugal projection (Saldana et al., 1996; Bajo et al., 2007) geared toward the ipsilateral side, along with an ipsilateral predominance of changes in gene expression suggest a local consequence of terminal degeneration in the IC. The biological functions of genes, whose regulation is affected, indicate that beyond an inflammatory response an emergent plastic process, probably related with sprouting, and pruning on the adult collicular network, takes place bilaterally in the ICs after short-term post-lesion.

\section{THE IPSI- AND CONTRALATERAL IC 90 DAYS AFTER THE LESION TO THE CORTEX}

A much larger gene expression regulation pattern was found in the IC 90 days after the cortical lesion. Microarray comparisons between control and ipsilateral IC showed that changes affected remarkably genes involved in apoptosis. We found an up-regulation in Programmed cell death 10 ( $P d c d 10)$ whose overexpression is sufficient to induce neuronal apoptosis (Lin et al., 2010). Fission 1 (Fis1) which participates in apoptotic mitochondrial fission (Youle and Karbowski, 2005) was also up-regulated and so were Growth arrest-specific 2 (Gas2) gene, a substrate of Caspase-3 (Sgorbissa et al., 1999), and Cytochrome c oxidase subunit VIIb (Cox7b) which is one of the last subunits that join the assembling cytochrome oxidase complex inducing apoptosis and affecting mitochondrial integrity (Fornuskova et al., 2010). We also found an up-regulation in Calpain 7 (Capn7), which is associated after brain injury with neuron death and axonal degeneration
(Saatman et al., 2010). In addition, we detected down-regulation of the Calsyntenin 3 (Clstn3), a gene which overexpression accelerates neuronal death (Uchida et al., 2011). All this strongly suggests an ongoing cell death process in the ipsilateral IC at 90 days postlesion. However we did not find changes in the expression of initiator or effector caspases genes triggering the apoptotic process. This could be related with limited microarray sensitivity. On the other hand, deprivation of auditory nerve input in adult animals does not result in significant neuronal loss in the cochlear nuclei (Harris et al., 2005), supporting the idea that in the auditory system mature neurons are less sensitive to apoptotic cell death. It could be that the regulation of apoptotic cascade genes observed by us may be related to other cellular pathways in which all these genes also performed a key role. Further specific proteomic experiments of caspases cell cascades will be needed to elucidate this problem, mainly because the regulation of apoptotic cascades is complex and involves transcriptional control as well as posttranscriptional protein modifications (Culmsee and Landshamer, 2006).

We also found in the ipsilateral IC 90 days after the lesion down-regulation of Myelin-associated glycoprotein (Mag), a gene able to inhibit axon regeneration after injury (Yiu and He, 2003). Studies in vivo demonstrate a modest but significant enhancement of axon regeneration in mice lacking Mag (Schnaar and Lopez, 2009). Down-regulation of this gene in our material could be an indication of axon elongation and indirectly of a sprouting process subsequent to lesion in the ipsilateral IC. However, at this same post-lesion time an oligodendrocyte-specific protein, Claudin 11 (Cldn11), which encodes a molecular component present in tight junctions and which is also is involved in axon myelination, was down-regulated. This result probably indicates an inefficient axon myelination during axon elongation. Cldn11 down-regulation may affect biophysical properties of myelinated axons in the IC, because it is known that Cldn11-null mice present a $60 \%$ decrease in conduction velocity (Devaux and Gow, 2008). A low effective compartmentalization of the myelin sheet of sprouting axon collaterals may be in accordance with previous results in which after 90 days of cortical lesion, sound stimulation-induced c-Fos immunoreactivity in the IC was only partially recovered (Clarkson et al., 2010a). In correspondence with this low activity in the IC at this survival time after the cortical lesion, genes related with synaptic activity also were affected with down-regulation in Synaptotagmin-11 (Syt11, a Ca ${ }^{2+}$-sensor during vesicular trafficking, Inoue et al., 2007), Calcium channel - voltage-dependent - $\gamma 3$ (Cacng3, a gene with modulatory effects on the electrophysiological characteristic of the Cav2.1 channel, Rousset et al., 2001) and also in Potassium inwardly rectifying channel, subfamily J, member 16 (Kcnj16) which plays a physiological role in the potassium buffering-action of brain astrocytes (Hibino et al., 2004). Holt et al. (2005) showed by RT-qPCR a rearrangement in synaptic transmission genes in the IC 90 days after cochlear ablation, with regulation affecting several glutamate and GABA receptors genes, supporting the hypothesis that, after long-term post-lesion, the adult auditory system is able to modify the gene neurotransmission machinery in the IC even after lack of auditory activity. Glial related genes such as Connexin 30 and 43, which are specific gap junction proteins that mediate cell-to-cell communication (Gemel et al., 2008) and Cadherin 13 involved in regulation of cell growth, survival, and 
astrocyte proliferation (Huang et al., 2003) were down-regulated. Recently studies from connexin 30 and 43 show that these gap junctions mediate astroglial networks scale synaptic activity, as they define the concentrations and dynamics of extracellular ions and neurotransmitters during synaptic activity (Pannasch et al., 2011). These glia gene regulations after ablation are important for tripartite synapses model, in which brain function actually arises from the coordinated activity of a network comprising both neurons and glia (Perea et al., 2009).

The idea that in the ipsilateral IC 90 days after cortical ablation plastic or adaptive reorganizations have been switched on is also reinforced by previous data showing that sound-induced c-Fos immunoreactivity progressively increases from 90 to 180 days after cortical ablation (Clarkson et al., 2010a), showing that neuronal activity is still on its way to recovery.

After 90 days of the lesion, the contralateral IC showed upregulation in genes involved in neurotransmission/signal propagation/synaptic plasticity such as Sodium channel, type IV, beta $(S c n 4 b)$ whose overexpression induces neurite outgrowth, causes thickening of dendrites and increases the post synaptic density of neuronal spines (Oyama et al., 2006). Also Potassium voltage channel, shaker related subfamily, member 6 (Kcna6) was up-regulated. This potassium channel regulates miniature inhibitory postsynaptic currents (mIPSCs) by regulating glycine release from the endings (Shoudai et al., 2007). In astrocytes Kcna6 underlies part of the delayed rectifier potassium current (Smart et al., 1997). Another family of potassium channels like KCNQ5 and KCNK15 has been localized to neurons in the IC and are modulated by hearing loss (Caminos et al., 2007; Dong et al., 2009). Furthermore, up-regulation in opioid receptor, sigma 1 (Oprs1), found in our results, may be related to its role in neuronal plasticity, enhancing growth factor-induced neurite outgrowth (Hashimoto, 2010; Ruscher et al., 2011), and also regulating both $\mathrm{Ca}^{2+}$ entry and $\mathrm{Ca}^{2+}$ mobilization from endoplasmic reticulum stores (Monnet, 2005). Another opioid receptor involved in nociception, Opioid receptor-like 1 (Oprl1) was also up-regulated, and is able to decrease acetylcholine release and dopamine release and elevates extracellular glutamate and GABA levels (Schlicker and Morari, 2000). All these changes were accompanied by an up-regulation in genes for neurotransmitter delivery at synaptic terminals. For example, in our material up-regulation of SV2a which exerts a main role in neurotransmitter uptake, vesicle targeting, and membrane fusion (Elferink and Scheller, 1995), as well as Synaptogyrin 1 and 3 (Syngr1 and 3), both of which play an essential function in synaptic plasticity without being required for neurotransmitter release (Belizaire et al., 2004). These data agrees with the idea that in adult animals the contralateral IC that loses the weaker projection from the cortex is still able, after long-term post-lesion, to enhance its genetic machinery to try to compensate the imbalance induced by lost cortical connections. This compensation could be the result of fine plastic modulations, which may include sprouting, pruning, and neurotransmission rearrangement. According to this idea, we also found an increase in Hippocalcin ( $\mathrm{Hpca}$ ) which encodes a calcium-binding protein considered relevant for synaptic plasticity, acting as a molecular link between $\mathrm{Ca}^{2+}$ entry through NMDA receptor and the subsequent endocytosis of AMPA receptor subunits in long-term depression (LTD; Palmer et al., 2005). Also it was shown that Hpca overexpression dramatically elongated neurites (Oh et al., 2008). Similarly, Dopamine receptor D1 interacting protein (Drd1ip) a known brain plasticity gene (Kruusmagi et al., 2007) that plays a specialized role in removal of synaptic AMPA receptor (Davidson et al., 2009) was up-regulated. So it was $N$-myc downstream regulate gene 4 ( Ndrg4) a contributor to neuronal differentiation, neurite formation, cell progression, and survival (Takahashi et al., 2005; Schilling et al., 2009), Neural proliferation, differentiation, and control 1 (Npdc1) gene, which is able to down-regulate the proliferation of neural precursors (Dupont et al., 1997), and Spinster that is a negative regulator of synaptic regrowth (Sweeney and Davis, 2002) were also up-regulated. This balance between regrowth and growth suppression gene expression seems to be important to demonstrate rewiring network processes in the contralateral IC 90 days after lesion through activation of mechanisms involve in neuronal regulation.

In summary, up-regulation in genes related to axonal growth, receptor expression, and trafficking as well in channels and synaptic machinery may be compatible with plastic reorganization that is more active in the contralateral IC. These differences in the timing for plasticity activation between both sides may be explained by the asymmetrical loss of excitation due to the asymmetrical density of the descending connections from the cortex.

\section{COMPARING IPSI- AND CONTRALATERAL CHANGES AT 15 AND 90 DAYS POST-LESION}

Comparison between ipsi- and contralateral IC after 15 days shows a small number of altered genes (14), contrasting with the larger number of regulated genes in the comparison (ipsi- vs. contralateral) after 90 days subsequent to the cortical lesion (1659 genes). Gene expression analysis between ipsi- and contralateral IC after 90 days following the cortical lesion showed up-regulation in potassium and chloride channels, and cholinergic, serotoninergic, glycinergic receptors in the contralateral IC. Biological function of up-regulated genes speaks in favor of a more active synaptic plasticity in the contralateral IC after long-term postlesion. In particular, the NMDA receptor subunit coded by Grin1 (glutamate receptor, ionotropic, $\mathrm{N}$-methyl D-aspartate 1 ) and its associated protein coded by Grina (glutamate receptor, ionotropic, $N$-methyl D-aspartate-associated protein 1) were up-regulated in the contralateral IC. NMDA receptors are important for activitydependent synaptic plasticity (Kalev-Zylinska et al., 2009; Rebola et al., 2010). In vitro experiments demonstrated that activation of NMDA receptors mediated a dramatic increase of both $c$-fos expression and intracellular calcium (Lerea et al., 1992). In a previous work both Calretinin (an indirect marker of $\mathrm{Ca}^{2+}$ influxClarkson et al., 2010b) and c-Fos in the IC contralateral to the lesion (Clarkson et al., 2010a) showed stronger immunoreactivity relative to the ipsilateral side. Future experiments will be need to demonstrate in our in vivo model a direct correlation among NMDA receptor activation, c-Fos activation, and changes in the intracellular $\mathrm{Ca}^{2+}$ concentration.

An extensive group of genes potentially involved in neurotransmitter release, such as four members of the Synaptotagmin family (Syt1, 2, 11, and 12; Chapman, 2008; Rizo and Rosenmund, 2008; Sudhof and Rothman, 2009), were 
up-regulated in the contralateral side. In addition, genes involved both in expression and trafficking of Synaptotagmin family members, such as the SV2 family ( $S V 2 a, S V 2 c$, and SV2 related protein; Nowack et al., 2010) were also up-regulated in the contralateral IC. Not only were receptors and synaptic vesicle fusion genes upregulated in the contralateral side after long-term lesion, but also this rearrangement was accompanied by an up-regulation in key enzymes for GABA (4-aminobutyrate aminotransferase, Abat, and Glutamic acid decarboxylase 1, Gad1), glycine (Glycyl-tRNA synthetase, Gars), glutamate (Glutaminyl-tRNA synthetase, Qars) and endocannabinoid synthesis (Dyacylglycerol lipase alpha, Dagla), all of them key components in short and long-term plastic synaptic changes. In addition, neurotransmitter transporters were upregulated in the contralateral IC after long-term cortical ablation (for neuronal glutamate: Vesicular glutamate transporter 2, VGlut2, or solute carrier family 17 member 6, Slc17a6; for proline: Slc6a7; for glycine: Slc6a9; for GABA: Slc6a11 and Slc32a1; and for glutamate: Slc1a3 or GLAST). Up-regulation of both enzymes and transporter genes clearly suggests a post-lesion shift in the synthesis and recycling of neurotransmitters. These findings support the idea of a better recovery of neurotransmission in the contralateral IC probably due to the comparatively lower loss of excitation in that side after cortical lesion. All these data also suggest activitydependent compensatory mechanisms in the contralateral IC, counteracting the most affected ipsilateral IC. In summary, these changes in gene expression are important due to the claim that regulation depends on the extent of deafferentation, and even in

\section{REFERENCES}

Aagaard, A., Listwan, P., Cowieson, N., Huber, T., Ravasi, T., Wells, C. A., et al. (2005). An inflammatory role for the mammalian carboxypeptidase inhibitor latexin: relationship to cystatins and the tumor suppressor TIG1. Structure 13, 309-317.

Bajo, V. M., Nodal, F. R., Bizley, J. K., Moore, D. R., and King, A. J. (2007). The ferret auditory cortex: descending projections to the inferior colliculus. Cereb. Cortex 17, 475-491.

Belizaire, R., Komanduri, C., Wooten, K., Chen, M., Thaller, C., and Janz, R. (2004). Characterization of synaptogyrin 3 as a new synaptic vesicle protein. J. Comp. Neurol. 470, 266-281.

Benoit, C. E., Rowe, W. B., Menards, C., Sarret, P., and Quirion, R. (2011). Genomic and proteomic strategies to identify novel targets potentially involved in learning and memory. Trends Pharmacol. Sci. 32, 43-52.

Birthelmer, A., Ehret, A., Amtage, F., Forster, S., Lehmann, O., Jeltsch, H., et al. (2003). Neurotransmitter release and its presynaptic modulation in the rat hippocampus after selective damage to cholinergic or/and serotonergic afferents. Brain Res. Bull. 59, 371-381.
Bledsoe, S. C. Jr., Nagase, S., Miller, J. M., and Altschuler, R. A. (1995). Deafness-induced plasticity in the mature central auditory system. Neuroreport 7, 225-229.

Block, F., Dihne, M., and Loos, M. (2005). Inflammation in areas of remote changes following focal brain lesion. Prog. Neurobiol. 75, 342-365.

Bowen, G. P., Lin, D., Taylor, M. K., and Ison, J. R. (2003). Auditory cortex lesions in the rat impair both temporal acuity and noise increment thresholds, revealing a common neural substrate. Cereb. Cortex 13, 815-822.

Bullitt, E. (1995). Expression of c-foslike protein as a marker for neuronal activity following noxious stimulation in the rat. J. Comp. Neurol. 296, 517-530.

Bush, A. L., and Hyson, R. L. (2008). Effects of lithium and deafferentation on expression of glycogen synthase kinase-3beta, NFkappaB, betacatenin, and pCreb in the chick cochlear nucleus. Brain Res. 1203, 18-25.

Butz, M., van Ooyen, A., and Worgotter, F. (2009). A model for cortical rewiring following deafferentation and focal stroke.

adult animals it is larger after long-term post-lesion with specific changes aimed at recovering activity loss in IC neurons.

\section{AUTHOR CONTRIBUTION}

Cheryl Clarkson Performed experiments, prepared figures and wrote the manuscript. M. Javier Herrero-Turrión. Performed RTqPCRs experiments, analyzed statistically microarray data and drafted the manuscript. Miguel A. Merchán. Designed, coordinated, and supervised the study. All authors read and agreed the paper content.

\section{ACKNOWLEDGMENTS}

The authors would like to thank Dr. José Juiz for his critical review and very helpful suggestions and Ignacio Plaza for his excellent technical assistance. Financial support for this investigation was provided by the grant BFU2009-13754-CO2 from the Spanish Ministerio de Investigación e Innovación (Minciin).

\section{SUPPLEMENTARY MATERIAL}

The Supplementary Material for this article can be found online at http://www.frontiersin.org/Neural_Circuits/10.3389/ fncir.2012.00086/abstract

Datasheet 1 | Naïve control vs. 15 days and 90 days post-lesion.

\section{Datasheet 2 | Primers PCR arrays.}

Datasheet 3 | Funtional annotation of diferentially expresed genes.

Front. Comput. Neurosci. 3:10. doi:10.3389/neuro.10.010.2009

Caminos, E., Garcia-Pino, E., MartinezGalan, J. R., and Juiz, J. M. (2007). The potassium channel KCNQ5/Kv7.5 is localized in synaptic endings of auditory brainstem nuclei of the rat. J. Comp. Neurol. 505, 363-378.

Chapman, E. R. (2008). How does synaptotagmin trigger neurotransmitter release? Annu. Rev. Biochem. 77, 615-641.

Clarkson, C., Juíz, J. M., and Merchán, M. A. (2010a). Long-term regulation in calretinin staining in the rat inferior colliculus after unilateral auditory cortical ablation. J. Comp. Neurol. 518, 4261-4276.

Clarkson, C., Juíz, J. M., and Merchán, M. A. (2010b). Transient downregulation of sound-induced c-fos protein expression in the inferior colliculus after ablation of the auditory cortex. Front. Neuroanat. 4:141. doi:10.3389/fnana.2010.00141

Clarkson, C., López, D. E., and Merchán, M. A. (2010c). Long-term functional recovery in the rat auditory system after unilateral auditory cortex ablation. Acta Otolaryngol. 130, 326-332.
Culmsee, C., and Landshamer, S. (2006). Molecular insights into mechanisms of the cell death program: role in the progression of neurodegenerative disorders. Curr. Alzheimer Res. 3, 269-283.

Davidson, H. T., Xiao, J., Dai, R., and Bergson, C. (2009). Calcyon is necessary for activity-dependent AMPA receptor internalization and LTD in CA1 neurons of hippocampus. Eur. J. Neurosci. 29, 42-54.

Dennis, G. Jr., Sherman, B. T., Hosack, D. A., Yang, J., Gao, W., Lane, H. C., et al. (2003). DAVID: database for annotation, visualization, and integrated discovery. Genome Biol. 4, P3.

Devaux, J., and Gow, A. (2008). Tight junctions potentiate the insulative properties of small CNS myelinated axons. J. Cell Biol. 183, 909-921.

Dong, S., Mulders, W. H., Rodger, J., and Robertson, D. (2009). Changes in neuronal activity and gene expression in guinea-pig auditory brainstem after unilateral partial hearing loss. Neuroscience 159, 1164-1174.

Druga, R., and Syka, J. (2001). Effect of auditory cortex lesions on NADPHdiaphorase staining in the inferior colliculus of rat. Neuroreport 12, 1555-1559. 
Dupont, E., Sansal, I., Toru, D., Evrard, C., and Rouget, P. (1997). Identification of NPDC-1, gene involved in the control of proliferation and differentiation of neural and glial precursors. C. R. Seances Soc. Biol. Fil. 191, 95-104.

Edeline, J. M., and Weinberger, N. M. (1991a). Subcortical adaptive filtering in the auditory system: associative receptive field plasticity in the dorsal medial geniculate body. Behav. Neurosci. 105, 154-175.

Edeline, J. M., and Weinberger, N. M. (1991b). Thalamic short-term plasticity in the auditory system: associative returning of receptive fields in the ventral medial geniculate body. Behav. Neurosci. 105, 618-639.

Edeline, J. M., and Weinberger, N. M. (1992). Associative retuning in the thalamic source of input to the amygdala and auditory cortex: receptive field plasticity in the medial division of the medial geniculate body. Behav. Neurosci. 106, 81-105.

Elferink, L. A., and Scheller, R. H. (1995). Synaptic vesicle proteins and regulated exocytosis. Prog. Brain Res. 105, 79-85.

Feliciano, M., and Potashner, S. J. (1995). Evidence for a glutamatergic pathway from the guinea pig auditory cortex to the inferior colliculus. J. Neurochem. 65, 1348-1357.

Fornuskova, D., Stiburek, L., Wenchich, L., Vinsova, K., Hansikova, H., and Zeman, J. (2010). Novel insights into the assembly and function of human nuclear-encoded cytochrome $c$ oxidase subunits 4 , 5a, 6a, 7a, and 7b. Biochem. J. 428, 363-374.

Gao, E., and Suga, N. (1998). Experience-dependent corticofugal adjustment of midbrain frequency map in bat auditory system. Proc. Natl. Acad. Sci. U.S.A. 95, 12663-12670.

Gao, E., and Suga, N. (2000). Experience-dependent plasticity in the auditory cortex and the inferior colliculus of bats: role of the corticofugal system. Proc. Natl. Acad. Sci. U.S.A. 97, 8081-8086.

Gemel, J., Lin, X., Collins, R., Veenstra, R. D., and Beyer, E. C. (2008). Cx30.2 can form heteromeric gap junction channels with other cardiac connexins. Biochem. Biophys. Res. Commun. 369, 388-394.

Harris, J. A., Hardie, N. A., Bermingham-McDonogh, O., and Rubel, E. W. (2005). Gene expression differences over a critical period of afferent-dependent neuron survival in the mouse auditory brainstem. J. Comp. Neurol. 493, 460-474.

Hashimoto, K. (2010). Role of sigma1 receptors in neural plasticity and in antipsychotic action. Nihon Shinkei Seishin Yakurigaku Zasshi 30, 123-127.

Hibino, H., Fujita, A., Iwai, K., Yamada, M., and Kurachi, Y. (2004). Differential assembly of inwardly rectifying $\mathrm{K}+$ channel subunits, Kir4.1 and Kir5.1, in brain astrocytes. J. Biol. Chem. 279, 44065-44073.

Holt, A. G., Asako, M., Duncan, R. K., Lomax, C. A., Juíz, J. M., and Altschuler, R. A. (2006). Deafness associated changes in expression of two-pore domain potassium channels in the rat cochlear nucleus. Hear. Res. 216-217, 146-153.

Holt, A. G., Asako, M., Lomax, C. A., MacDonald, J. W., Tong, L., Lomax, M. I., et al. (2005). Deafness-related plasticity in the inferior colliculus: gene expression profiling following removal of peripheral activity. $J$. Neurochem. 93, 1069-1086.

Howley, R., Kinsella, P., Buckley, P. G., Alcock, L., Jansen, M., Heffernan, J., et al. (2012). Comparative genomic and proteomic analysis of high grade glioma primary cultures and matched tumor in situ. Exp. Cell Res. 318, 2245-2256.

Huang, D. W., Sherman, B. T., and Lempicki, R. A. (2009). Systematic and integrative analysis of large gene lists using DAVID bioinformatics resources. Nat. Protoc. 4, 44-57.

Huang, Z. Y., Wu, Y., Hedrick, N., and Gutmann, D. H. (2003). Tcadherin-mediated cell growth regulation involves $\mathrm{G} 2$ phase arrest and requires p21(CIP1/WAF1) expression. Mol. Cell. Biol. 23, 566-578.

Illing, R. B., Kraus, K. S., and Meidinger, M. A. (2005). Reconnecting neuronal networks in the auditory brainstem following unilateral deafening. Hear. Res. 206, 185-199.

Illing, R. B., and Reisch, A. (2006). Specific plasticity responses to unilaterally decreased or increased hearing intensity in the adult cochlear nucleus and beyond. Hear. Res. 216-217, 189-197.

Inoue, S., Imamura, A., Okazaki, Y., Yokota, H., Arai, M., Hayashi, N., et al. (2007). Synaptotagmin XI as a candidate gene for susceptibility to schizophrenia. Am. J. Med. Genet. B Neuropsychiatr. Genet. 144B, 332-340.

Jen, P. H., and Zhang, J. P. (1999). Corticofugal regulation of excitatory and inhibitory frequency tuning curves of bat inferior collicular neurons. Brain Res. 841, 184-188.
Kalev-Zylinska, M. L., Symes, W., Young, D., and During, M. J. (2009). Knockdown and overexpression of NR1 modulates NMDA receptor function. Mol. Cell. Neurosci. 41, 383-396.

Kandler, K. (2004). Activity-dependent organization of inhibitory circuits: lessons from the auditory system. Curr. Opin. Neurobiol. 14 96-104.

Keuroghlian, A. S., and Knudsen, E. I. (2007). Adaptive auditory plasticity in developing and adult animals. Prog. Neurobiol. 82, 109-121.

Kolset, S. O., and Pejler, G. (2011). Serglycin: a structural and functional chameleon with wide impact on immune cells. J. Immunol. 187, 4927-4933.

Kolset, S. O., and Tveit, H. (2008). Serglycin - structure and biology. Cell. Mol. Life Sci. 65, 1073-1085.

Kovacs, K. J. (2008). Measurement of immediate-early gene activation-cfos and beyond. J. Neuroendocrinol. 20, 665-672.

Kruusmagi, M., Zelenin, S., Brismar, H., and Scott, L. (2007). Intracellular dynamics of calcyon, a neuron-specific vesicular protein. Neuroreport 18, 1547-1551.

Lerea, L. S., Butler, L. S., and $\mathrm{McNa}$ mara, J. O. (1992). NMDA and nonNMDA receptor-mediated increase of c-fos mRNA in dentate gyrus neurons involves calcium influx via different routes. J. Neurosci. 12, 2973-2981.

Lin, C., Meng, S., Zhu, T., and Wang, X. (2010). PDCD10/CCM3 acts downstream of \{gamma\}-protocadherins to regulate neuronal survival. J. Biol. Chem. 285, 41675-41685.

Lyons, M. R., and West, A. E (2011). Mechanisms of specificity in neuronal activity-regulated gene transcription. Prog. Neurobiol. 94 259-295.

Ma, X., and Suga, N. (2005). Long-term cortical plasticity evoked by electric stimulation and acetylcholine applied to the auditory cortex. Proc. Natl. Acad. Sci. U.S.A. 102, 9335-9340.

Malmierca, M. S., and Merchán, M. (2004). "The auditory system", in The Rat Nervous System, ed. G. Paxinos (San Diego: Academic Press), 995-1080.

McAlpine, D., Martin, R. L., Mossop, J. E., and Moore, D. R. (1997). Response properties of neurons in the inferior colliculus of the monaurally deafened ferret to acoustic stimulation of the intact ear. J. Neurophysiol. 78, 767-779.
Monnet, F. P. (2005). Sigma-1 receptor as regulator of neuronal intracellular $\mathrm{Ca} 2+$ : clinical and therapeutic relevance. Biol. Cell 97, 873-883.

Norena, A. J., and Eggermont, J. J. (2006). Enriched acoustic environment after noise trauma abolishes neural signs of tinnitus. Neuroreport 17, 559-563.

Nowack, A., Yao, J., Custer, K. L., and Bajjalieh, S. M. (2010). SV2 regulates neurotransmitter release via multiple mechanisms. Am. J. Physiol. Cell Physiol. 299, C960-C967.

Nwabueze-Ogbo, F. C., Popelar, J., and Syka, J. (2002). Changes in the acoustically evoked activity in the inferior colliculus of the rat after functional ablation of the auditory cortex. Physiol. Res. 51(Suppl. 1), S95-S104.

Oh, D. Y., Cho, J. H., Park, S. Y., Kim, Y. S., Yoon, Y. J., Yoon, S. H., et al. (2008). A novel role of hippocalcin in bFGF-induced neurite outgrowth of H19-7 cells. J. Neurosci. Res. 86 1557-1565.

Oyama, F., Miyazaki, H., Sakamoto, N., Becquet, C., Machida, Y., Kaneko, K., et al. (2006). Sodium channel beta4 subunit: down-regulation and possible involvement in neuritic degeneration in Huntington's disease transgenic mice. J. Neurochem. 98, 518-529.

Palmer, C. L., Lim, W., Hastie, P. G., Toward, M., Korolchuk, V. I., Burbidge, S. A., et al. (2005). Hippocalcin functions as a calcium sensor in hippocampal LTD. Neuron 47, 487-494.

Pannasch, U., Vargová, L., Reingruber, J., Ezan, P., Holcman, D., Giaume, C., et al. (2011). Astroglial networks scale synaptic activity and plasticity. Proc. Natl. Acad. Sci. U.S.A. 108, 8467-8472.

Paxinos, G., and Watson, C. (2005). The Rat Brain in Stereotaxic Coordinates, 5th Edn, San Diego: Elsevier Academic Press.

Perea, G., Navarrete, M., and Araque, A. (2009). Tripartite synapses: astrocytes process and control synaptic information. Trends Neurosci. 32, 421-431.

Perez-Otano, I., and Ehlers, M. D. (2005). Homeostatic plasticity and NMDA receptor trafficking. Trends Neurosci. 28, 229-238.

Popelar, J., Nwabueze-Ogbo, F. C., and Syka, J. (2003). Changes in neuronal activity of the inferior colliculus in rat after temporal inactivation of the auditory cortex. Physiol. Res. 52, 615-628.

Rebola, N., Srikumar, B. N., and Mulle, C. (2010). Activity-dependent 
synaptic plasticity of NMDA receptors. J. Physiol. 588( $\mathrm{Pt} 1)$, 93-99.

Riquelme, R., Saldana, E., Osen, K. K., Ottersen, O. P., and Merchán, M. A. (2001). Colocalization of GABA and glycine in the ventral nucleus of the lateral lemniscus in rat: an in situ hybridization and semiquantitative immunocytochemical study. J. Comp. Neurol. 432, 409-424.

Rizo, J., and Rosenmund, C. (2008). Synaptic vesicle fusion. Nat. Struct. Mol. Biol. 15, 665-674.

Rousset, M., Cens, T., Restituito, S., Barrere, C., Black, J. L. III, McEnery, M. W., and Charnet, P. (2001). Functional roles of gamma2, gamma3 and gamma4, three new $\mathrm{Ca} 2+$ channel subunits, in P/Q-type $\mathrm{Ca} 2+$ channel expressed in Xenopus oocytes. J. Physiol. (Lond.) 532, 583-593.

Rubio, M. E. (2006). Redistribution of synaptic AMPA receptors at glutamatergic synapses in the dorsal cochlear nucleus as an early response to cochlear ablation in rats. Hear. Res. 216-217, 154-167.

Ruscher, K., Shamloo, M., Rickhag, M., Ladunga, I., Soriano, L., Gisselsson, L., et al. (2011). The sigma-1 receptor enhances brain plasticity and functional recovery after experimental stroke. Brain 134, 732-746.

Rutkowski, R. G., and Weinberger, N. M. (2005). Encoding of learned importance of sound by magnitude of representational area in primary auditory cortex. Proc. Natl. Acad. Sci. U.S.A. 102, 13664-13669.

Rybalko, N., Suta, D., Nwabueze-Ogbo, F., and Syka, J. (2006). Effect of auditory cortex lesions on the discrimination of frequency-modulated tones in rats. Eur. J. Neurosci. 23, 1614-1622.

Saatman, K. E., Creed, J., and Raghupathi, R. (2010). Calpain as a therapeutic target in traumatic brain injury. Neurotherapeutics 7, 31-42.

Saldana, E., Feliciano, M., and Mugnaini, E. (1996). Distribution of descending projections from primary auditory neocortex to inferior colliculus mimics the topography of intracollicular projections. J. Comp. Neurol. 371, $15-40$.
Schilling, S. H., Hjelmeland, A. B., Radiloff, D. R., Liu, I. M., Wakeman, T. P., Fielhauer, J. R., et al. (2009). NDRG4 is required for cell cycle progression and survival in glioblastoma cells. J. Biol. Chem. 284, 25160-25169.

Schlicker, E., and Morari, M. (2000). Nociceptin/orphanin FQ and neurotransmitter release in the central nervous system. Peptides 21, 1023-1029.

Schmittgen, T. D., and Livak, K. J. (2008). Analyzing real-time PCR data by the comparative $\mathrm{C}(\mathrm{T})$ method. Nat. Protoc. 3, 1101-1108.

Schnaar, R. L., and Lopez, P. H. (2009). Myelin-associated glycoprotein and its axonal receptors. J. Neurosci. Res. 87, 3267-3276.

Semple, M. N., and Kitzes, L. M. (1985). Single-unit responses in the inferior colliculus: different consequences of contralateral and ipsilateral auditory stimulation. J. Neurophysiol. 53, 1467-1482.

Sgorbissa, A., Benetti, R., Marzinotto, S., Schneider, C., and Brancolini, C. (1999). Caspase-3 and caspase-7 but not caspase- 6 cleave Gas2 in vitro: implications for microfilament reorganization during apoptosis. J. Cell. Sci. 112(Pt 23), 4475-4482.

Shoudai, K., Nonaka, K., Maeda, M., Wang, Z. M., Jeong, H. J., Higashi, H., et al. (2007). Effects of various $\mathrm{K}+$ channel blockers on spontaneous glycine release at rat spinal neurons. Brain Res. 1157, 11-22.

Smart, S. L., Bosma, M. M., and Tempel, B. L. (1997). Identification of the delayed rectifier potassium channel, Kv1.6, in cultured astrocytes. Glia 20, 127-134.

Stevens, B., Allen, N. J., Vazquez, L. E., Howell, G. R., Christopherson, K. S., Nouri, N., et al. (2007). The classical complement cascade mediates CNS synapse elimination. Cell 131, 1164-1178.

Sudhof, T. C., and Rothman, J. E. (2009). Membrane fusion: grappling with SNARE and SM proteins. Science $323,474-477$

Sun, X., Xia, Q., Lai, C. H., Shum, D. K., Chan, Y. S., and He, J. (2007). Corticofugal modulation of acoustically induced Fos expression in the rat auditory pathway. J. Comp. Neurol. 501, 509-525.

Sweeney, S. T., and Davis, G. W. (2002). Unrestricted synaptic growth in spinster-a late endosomal protein implicated in TGF-beta-mediated synaptic growth regulation. Neuron 36, 403-416.

Takahashi, K., Yamada, M., Ohata, H., Honda, K., Yamada, M. (2005) Ndrg2 promotes neurite outgrowth of NGF-differentiated PC12 cells. Neurosci. Lett. 388, 157-162.

Turrigiano, G. (2012). Homeostatic synaptic plasticity: local and global mechanisms for stabilizing neuronal function. Cold Spring Harb. Perspect. Biol. 4, a005736. doi:10.1101/cshperspect.a005736

Uchida, Y., Nakano, S., Gomi, F., and Takahashi, H. (2011). Up-regulation of calsyntenin-3 by beta-amyloid increases vulnerability of cortical neurons. FEBS Lett. 585, 651-656.

Vale, C., and Sanes, D. H. (2002). The effect of bilateral deafness on excitatory and inhibitory synaptic strength in the inferior colliculus. Eur. J. Neurosci. 16, 2394-2404.

Vemuganti, R., Kalluri, H., Yi, J. H., Bowen, K. K., and Hazell, A. S. (2006). Gene expression changes in thalamus and inferior colliculus associated with inflammation, cellular stress, metabolism and structural damage in thiamine deficiency. Eur. J. Neurosci. 23, 1172-1188.

Vitureira, N., Andres, R., PerezMartinez, E., Martinez, A., Bribian, A., Blasi, J., et al. (2010). Podocalyxin is a novel polysialylated neural adhesion protein with multiple roles in neural development and synapse formation. PLOS ONE 5, e12003. doi:10.1371/journal.pone. 0012003

Wang, H., Turner, J. G., Ling, L., Parrish, J. L., Hughes, L. F., and Caspary, D. M. (2009a). Age-related changes in glycine receptor subunit composition and binding in dorsal cochlear nucleus. Neuroscience 160 227-239.

Wang, H., Brozoski, T. J., Turner, J. G., Ling, L., Parrish, J. L., Hughes, L. F. et al. (2009b). Plasticity at glycinergic synapses in dorsal cochlear nucleus of rats with behavioral evidence of tinnitus. Neuroscience 164 747-759.
Wieloch, T., and Nikolich, K. (2006) Mechanisms of neural plasticity following brain injury. Curr. Opin. Neurobiol. 16, 258-264.

Yanagisawa, H., Miyashita, T., Nakano, Y., and Yamamoto, D. (2003). HSpinl, a transmembrane protein interacting with $\mathrm{Bcl}-2 / \mathrm{Bcl}-$ $\mathrm{xL}$, induces a caspase-independent autophagic cell death. Cell Death Differ. 10, 798-807.

Yata, K., Oikawa, S., Sasaki, R., Shindo, A., Yang, R., Murata, M., et al. (2011). Astrocytic neuroprotection through induction of cytoprotective molecules; a proteomic analysis of mutant P301S tau-transgenic mouse. Brain Res. 1410, 12-23.

Yiu, G., and He, Z. (2003). Signaling mechanisms of the myelin inhibitors of axon regeneration. Curr. Opin. Neurobiol. 13, 545-551.

Youle, R. J., and Karbowski, M. (2005). Mitochondrial fission in apoptosis. Nat. Rev. Mol. Cell Biol. 6, 657-663.

Zhang, Y., Suga, N., and Yan, J. (1997). Corticofugal modulation of frequency processing in bat auditory system. Nature 387 900-903.

Conflict of Interest Statement: The authors declare that the research was conducted in the absence of any commercial or financial relationships that could be construed as a potential conflict of interest.

Received: 22 May 2012; accepted: 29 October 2012; published online: 26 November 2012.

Citation: Clarkson C, Herrero-Turrión MJ and Merchán MA (2012) Cortical auditory deafferentation induces longterm plasticity in the inferior colliculus of adult rats: microarray and $q P C R$ analysis. Front. Neural Circuits 6:86. doi: 10.3389/fncir.2012.00086

Copyright (c) 2012 Clarkson, HerreroTurrión and Merchán. This is an openaccess article distributed under the terms of the Creative Commons Attribution License, which permits use, distribution and reproduction in other forums, provided the original authors and source are credited and subject to any copyright notices concerning any third-party graphics etc. 


\section{APPENDIX}

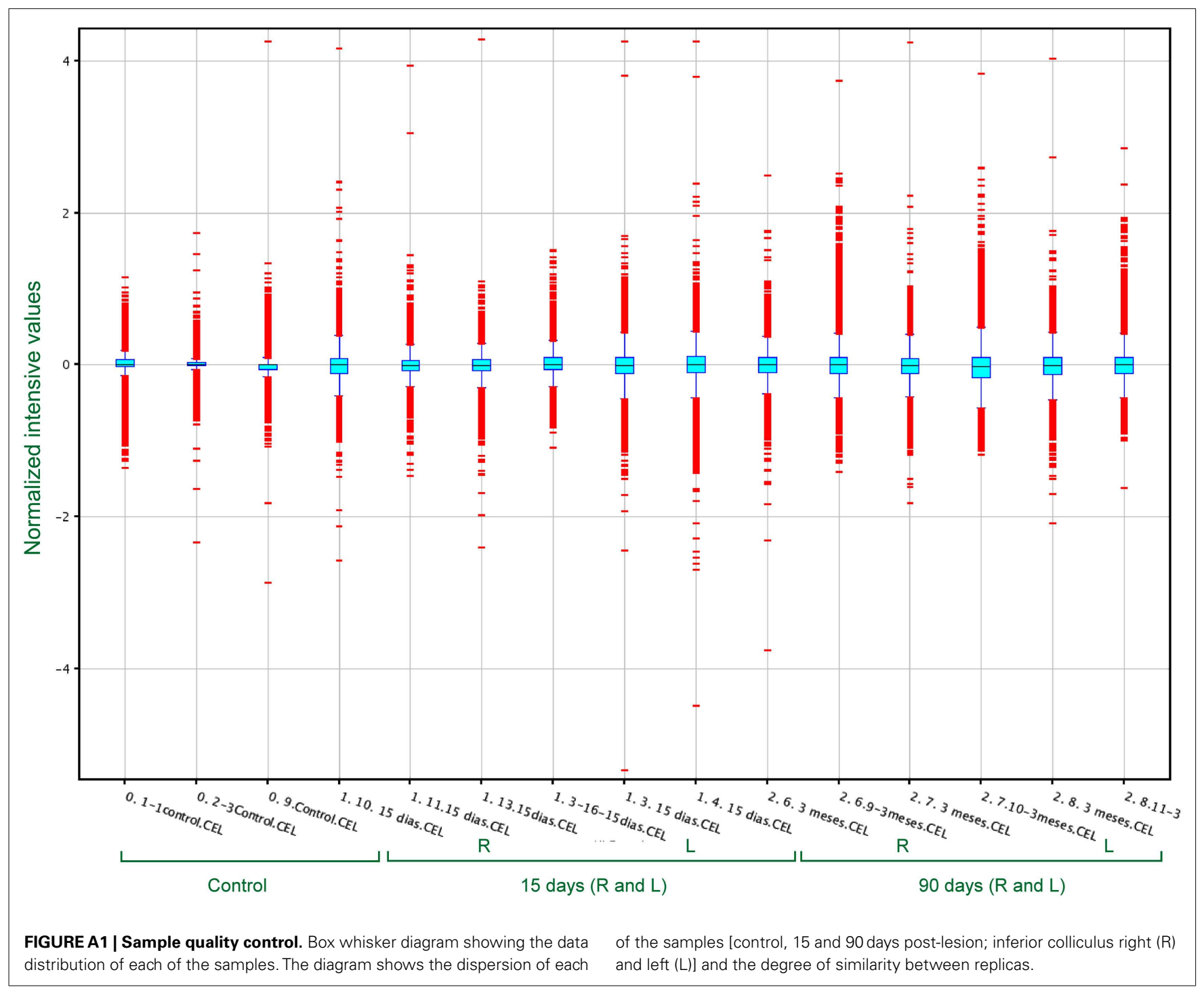

